Elsevier Editorial System(tm) for Talanta Manuscript Draft

Manuscript Number: TAL-D-16-00754R2

Title: MULTIRESIDUE TRACE ANALYSIS OF PHARMACEUTICALS, THEIR HUMAN METABOLITES AND TRANSFORMATION PRODUCTS BY FULLY AUTOMATED ON-LINE SOLIDPHASE EXTRACTION-LIQUID CHOMATOGRAPHY-TANDEM MASS SPECTROMETRY

Article Type: Research Paper

Keywords: LC-LC analysis, metabolites, transformation products, environmental waters, polarity switch

Corresponding Author: Dr. María Jesús García, PhD

Corresponding Author's Institution: LEQUIA, Institute of the Environment, University of Girona,

First Author: María Jesús García, PhD

Order of Authors: María Jesús García, PhD; Sara Rodriguez-Mozaz; Mira Petrovic; Damià Barcelo

Abstract: A novel, fully automated analytical methodology based on dual column liquid chromatography coupled to tandem mass spectrometry (LC-LCMS2) has been developed and validated for the analysis of 12

pharmaceuticals and 20 metabolites and transformation products in different types of water (influent and effluent wastewaters and surface water). Two LC columns were used - one for pre-concentration of the sample and the second for separation and analysis - so that water samples were injected directly in the chromatographic system. Besides the many advantages of the methodology, such as minimization of the sample volume required and its manipulation, compounds that ionize in positive mode and those that ionize in negative mode could be analyzed simultaneously without compromising the sensitivity. A comparative study of different mobile phases, gradients and LC pre-concentration columns was carried out to obtain the best analytical performance. Limits of detection (MLODs) achieved were in the low ng L-1 range for all the compounds. The method was successfully applied to study the presence of the target analytes in different wastewater and surface water samples collected near the city of Girona (Catalonia, Spain). Data on the environmental presence and fate of pharmaceutical metabolites and TPs is still scarce, highlighting the relevance of the developed methodology. 
Lyon, March 21 2016.

Dear Editor,

I am herewith enclosing the manuscript "Multiresidue trace analysis of pharmaceuticals, their human metabolites and transformation products by fully automated on-line solid phase extraction-liquid chromatography-tandem mass spectrometry" to be considered for publication in Talanta. All of the authors have read and approved the paper and it has not been published previously nor is it being considered by any other peer-reviewed journal.

The content of this paper fits accurately with the scope of this journal, as it contains the detailed development of a novel methodology of environmental analysis based on liquid-liquid chromatography, on-line solid phase extraction and MS/MS, and its practical application. The manuscript addresses the actual need of new analytical methodologies in which the number of pre-treatment steps and time required is minimized, as well as the amount of solvents used. On-line SPE by means of liquidliquid chromatography was the technique of choice to achieve this objective. Another added-value is that analyses are carried out in both positive and negative ionization mode in the same run (polarity-switch mode).

Besides, the methodology developed deals with the environmental presence at trace level of the main metabolites and transformation products of highly consumed pharmaceuticals, a subject with a present increasing concern due to the scarce information available on both their environmental levels and their potential derived ecotoxicological effects.

Sincerely yours:

Dr. María Jesús García Galán

ISA. Insitute des Sciénces Analytiques de Lyon. UMR 5280

5, rue de la Doua. 69100 Villeurbanne, France

E-mail address: chus3.garcia@gmail.com 
Editor's comments:

The authors follow the criterium of their original sending: use of capital and no capital letters in the headings and sub-headings at their preference. Examples: 2.1. Chemicals and reagents, 2.3. Analytical Methodology, 2.3.1. LC-LC Conditions, 2.3.2. UHPLC-MS2 analysis

AN: This has been corrected by the authors

Why the authors removed the titles of the publications in the list of references?

AN: the authors have followed the same format for the references as observed in other Talanta articles, including one of her own (García-Galán et al. Talanta 81(2010) 355-366)

"AN: we have contacted the researcher support from the Elsevier editorial and they have confirmed that there is actually no maximum limit for the number of figures and/or tables. We kindly ask to keep at least 6 figures+tables, as we send it now in our final version." The Editor has never considered the number of figures+tables as a Talanta or Elsevier rule, but as a function of the necessity and importance of them.

AN: the authors fully understand the editor's criteria and would like to keep the number of figures and tables as it is now, if the editor agrees. We consider they are quite informative and useful. 


\section{NOVELTY STATEMENT}

This work aimed to the development and successful application of a novel analytical methodology for the trace analysis of metabolites and transformation products of pharmaceuticals in different environmental waters, minimizing the analysis time and sample/solvent consumption, as well as improving the sensibility and robustness of the application. 


\section{HIGHLIGHTS}

- A novel methodology based on LC-LC/MS/MS was successfully developed and applied.

- The method reduces the number of pre-treatment steps and sample/solvent volume used.

- Simultaneous PI/NI mode analyses were performed without sensitivity loss.

- The environmental presence of 20 metabolites and TPs of PhACs was investigated.

- Brand new data on the environmental presence of metabolites and TPs is provided. 
${ }^{*}$ Graphical Abstract (for review)

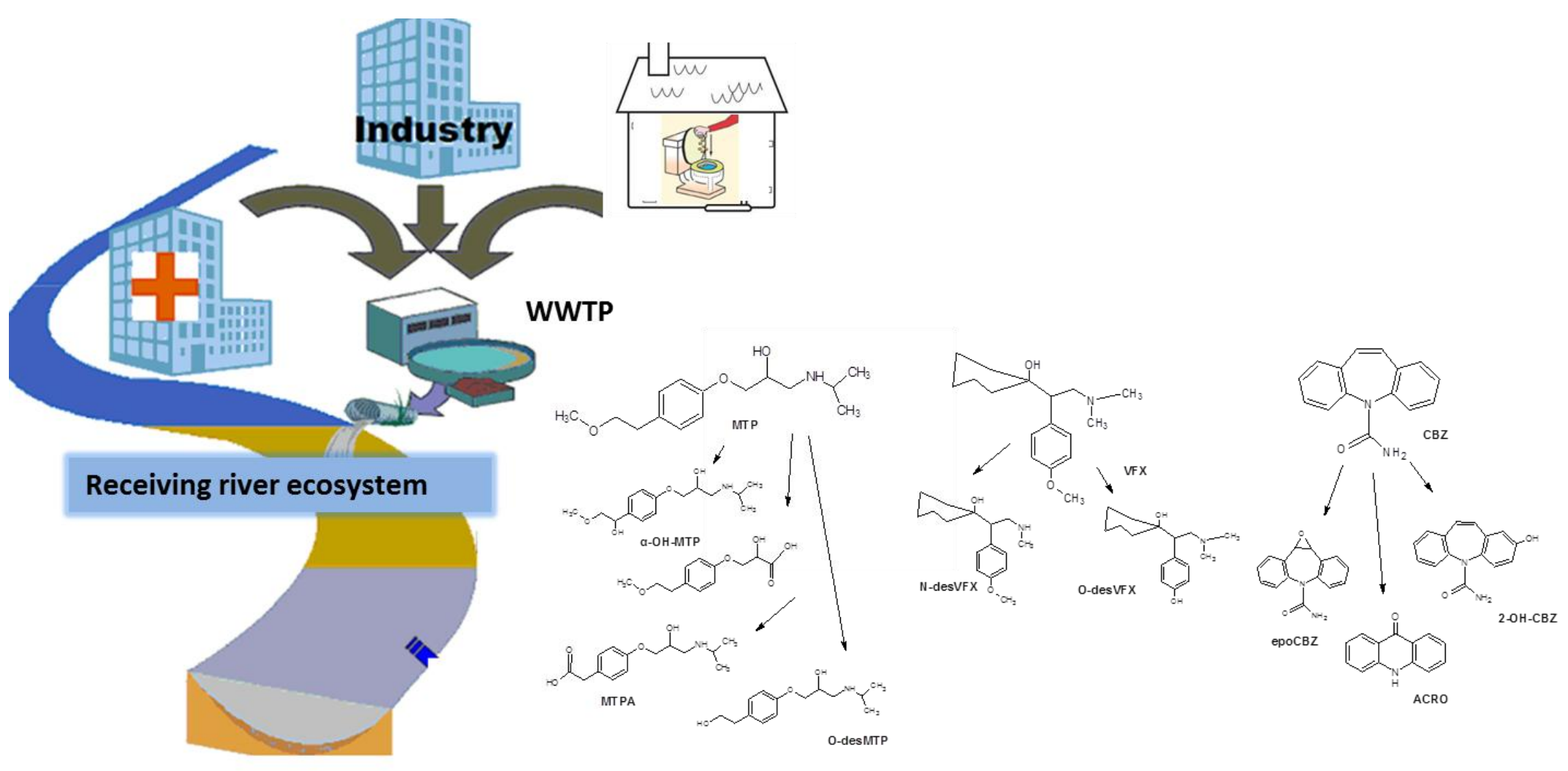




\title{
MULTIRESIDUE TRACE ANALYSIS OF PHARMACEUTICALS, THEIR HUMAN METABOLITES AND TRANSFORMATION PRODUCTS BY FULLY AUTOMATED ON-LINE SOLID-PHASE EXTRACTION-LIQUID CHROMATOGRAPHY-TANDEM MASS SPECTROMETRY
}

\author{
Ma Jesús García-Galán ${ }^{1,2 *}$, Mira Petrovic², Sara Rodríguez-Mozaz², Damià Barceló \\ 1. LEQUIA, Institute of the Environment, University of Girona, Campus Montilivi, E-17071, Girona, Spain \\ 2. ICRA, Catalan Institute for Water Research, Emili Grahit 101, E-17003 Girona, Spain
}

\section{ABSTRACTAbstract}

A novel, fully automated analytical methodology based on dual column liquid chromatography coupled to tandem mass spectrometry (LC-LC-MS ${ }^{2}$ ) has been developed and validated for the analysis of 12 pharmaceuticals and 20 metabolites and transformation products in different types of water (influent and effluent wastewaters and surface water). Two LC columns were used - one for pre-concentration of the sample and the second for separation and analysis - so that water samples were injected directly in the chromatographic system. Besides the many advantages of the methodology, such as minimization of the sample volume required and its manipulation, both compounds that ionize in positive and negative mode could be analyzed simultaneously without compromising the sensitivity. A comparative study of different mobile phases, gradients and LC pre-concentration columns was carried out to obtain the best analytical performance. Limits of detection (MLODs) achieved were in the low $\mathrm{ng} \mathrm{L}^{-1}$ range for all the compounds. The method was successfully applied to study the presence of the target analytes in different wastewater and surface water samples collected near the city of Girona (Catalonia, Spain). Data on the environmental presence and fate of pharmaceutical metabolites and TPs is still scarce, highlighting the relevance of the developed methodology.

Keywords: LC-LC analysis, metabolites, transformation products, environmental waters. 


\section{IntroductionATRODUCTION}

Thousands of tons of different classes of pharmaceutical active compounds (PhACs) are used on a regular basis in human and veterinary medicine worldwide. After their usage and excretion, it is highly probable that both the metabolites and the unchanged parent drug enter the environment [1]. Due to their physical-chemical properties, PhACs are generally hardly biodegradable and only partially removed by physical and standard biological treatment processes (conventional active sludge treatment, (CAS)) in wastewater treatment plants (WWTPs), and could also remain biologically active for long periods [2]. Consequently, several studies concluded that effluents from urban WWTPs should be considered one of the main entrance pathways of PhACs into the environment and therefore partly responsible for surface and marine water contamination [2-4]. The presence of PhACs in all kind of environmental waters has been widely documented during the last decades, at concentrations ranging from $\mathrm{ng} \mathrm{L}^{-1}$ to $\mu \mathrm{g} \mathrm{L}^{-1}$ [7-11]. Although information is still scarce on the ecotoxicity derived of PhACs under real environmental conditions, it is not expected that these concentrations levels for individual compounds could pose an acute risk. However, the combined effect of a mixture of compounds, sharing or not a common mechanism of action could be substantial [12]. Furthermore, the coexistence of the parent drugs with their human metabolites and transformation products (TPs) could also lead to additive, antagonistic and/or synergetic effects which are hard to predict and should be investigated. For instance, a photodegradation TP of DCF has proved to be phytotoxic against certain species of green algae [13], and the assessment of the ecotoxicity of other photoproducts of DCF and naproxen has provided the evidence that acute and chronic toxicity can be greater for these photoproducts than for the parent compounds $[14,15]$. Donner et al. [16] demonstrated that UV photoproducts of CBZ, acridine and acridone ( $A C R I, A C R O)$, were more toxic to certain aquatic organisms than the parent compound. Effective concentration values $\left(E_{50}\right)$ obtained after 15 min exposure for the antibiotic sulfapyridine (SPY) and its acetylated metabolite, $\mathrm{N}^{4}$-acetylsulfapyridine (acSPY), demonstrated that the marine bacteria Vibrio fischerii was more sensitive to the presence of the metabolite than to the original drug, and according to the European Directive 93/67/EEC [17], acSPY could be categorized as toxic [18]. On the other hand, it has been demonstrated that antimicrobial activity of several antibiotics is fully eliminated after advanced treatments such as ozonation [19], but other environmental degradative processes may not be so efficient against the bioactivity of these micropollutants. Majewsky et al. demonstrated that TPs of 
sulfamethoxazole (SMX) modified in the para (amino) group, such as 4-hydroxy-SMX or 4-nitroSMX, exhibited higher growth inhibiting properties than SMX against the marine bacteria Vibrio fischerii, and that these effects were additive [20].

Only recently, the environmental presence of human metabolites and TPs of PhACs has started to be considered within the scope of monitoring studies, and eventually regarded as potential elements of risk [7, 10, 21]. During treatment in the WWTP or once released onto the environment, PhACs (and their metabolites) can undergo biotic and abiotic transformation processes (microbial degradation, hydrolysis, photodegradation, oxidation, etc) yielding a potentially high number of new compounds of unknown elemental composition, stability and potency [7]. Human metabolites and TPs can also be identical; this is the case of 4'-OHdiclofenac (4-OH-DCF) and 5-OH-diclofenac, which account for approximately $22 \%$ of the excreted dose of DCF in the urine, but have also been detected as biodegradation products in DCF removal experiments by white rot fungi and identified also as photodegradation TPs [2224]. The same has been observed for the human metabolites of $\mathrm{CBZ}, 2-\mathrm{OH}$-carbamazepine and 10,11-epoxy-carbamazepine (2-OH-CBZ, epo-CBZ), detected after CBZ treatment with fungi [25] and also after its natural biodegradation in soils [26]. However, in many cases degradation pathways are not identical for PhACs, yielding different TPs.

Nowadays, the challenge for PhACs analysis at environmental levels in water matrices has shifted from reaching enough sensitivity and selectivity for their detection, which is generally accomplished using liquid chromatography followed by tandem mass spectrometry $\left(\mathrm{LC}-\mathrm{MS}^{2}\right)$ as analytical technique, to the reduction of the time of analysis, manipulation of the samples in a minimum number of steps and a reduced use of solvents. Analytical methodologies capable of detection at environmental levels $\left(\mathrm{pg} \mathrm{L}^{-1}\right)$, usually require a clean-up of the sample and pre-concentration of the target analytes based on solid phase extraction (SPE) off-line; SPE involves a certain number of steps that imply several hours of preparation, requiring also sample volumes of up to $100-1000 \mathrm{~mL}$ to obtain the desired sensitivity and the use of significant amounts of solvents [27, 28]. Taking this into account, on-line preconcentration has become one of the most suitable sample preparation approaches available. Previous works account for the many advantages of on-line SPE procedure, such as minimum sample manipulation by the analyst (lower probability of error), reduced sample volume required, reduced time and solvents used and improved throughput [9, 21, 29]. By means of dual column liquid chromatography switching system (LC-LC), ordinary on-line SPE has also 
been improved, as only one pre-concentration column is used for all the set of samples, instead of one SPE cartridge per sample [30].

Although several analytical methods for the determination of pharmaceuticals and TPs are currently available in the literature, the majority is based on off-line SPE [33-35] and the few works dealing with on-line SPE perform analyses in PI and NI mode separately $[10,36]$. The aim of this work is the development and optimization of a new, fast, robust and highthroughput multi-residue analytical method, based on on-line pre-concentration of the target analytes by means of Equan ${ }^{\mathrm{TM}}$ Direct Injection Technology, which permits simultaneous monitoring in either $\mathrm{PI}$ and $\mathrm{NI}$ mode in the same chromatographic run of 12 pharmaceuticals and 20 of their metabolites and TPs, in surface and wastewaters. The target PhACs were selected considering both their high consumption rates and environmental relevance (high occurrence in the environment). Metabolites and TPs were selected depending on their commercial availability and also considering the little information available regarding their environmental presence.

\section{AATERIALSAND METHODSMaterials and methods}

\subsection{Chemicals and reagents}

HPLC-grade solvents (water, methanol $(\mathrm{MeOH})$, acetone and acetonitrile (ACN)) and formic acid $(\mathrm{HCOOH})(98-100 \%)$ were supplied by Merck (Darmstadt, Germany) and Thermo Fisher Scientific (Franklin, MA, US). High purity standards (>99\%) of the pharmaceuticals acetaminophen (ACM), sulfamethoxazole (SMX), sulfapyridine (SPY), sulfamethazine (SMZ), venlafaxine (VFX), diazepam (DZP), carbamazepine (CBZ), diclofenac (sodium salt)(DCF), fluoxetine (FXT), metoprolol (MTP) and the metabolites norverapamil (norVPM), norfluoxetine (norFXT) and acridine (ACRI) were purchased from Sigma-Aldrich (St. Louis, MO, USA). High purity standards for the metabolites 4-nitro-sulfamethoxazole (4-nitro-SMX), 4'-hydroxydiclofenac (4-OH-DCF), diclofenac amide (adDCF), diclofenac acyl-B-D-glucuronide (gluDCF), acridone (ACRO), D,L-N-desmethylvenlafaxine (N-desVFX), D,L-O-desmethylvenlafaxine (OdesVFX), $\quad \mathrm{N}^{4}$-acetylsulfapyridine (acSPY), $\quad \mathrm{N}^{4}$-acetylsulfamethazine $\quad$ (acSMZ), $\quad \mathrm{N}^{4}$ acetylsulfamethoxazole (acSMX), desmethyldiazepam (norDZP), 3-OH-acetaminophen (3-OHACM), $\alpha$-hydroxymetoprolol ( $\alpha$-HMTP), metoprolol acid (MTPA), O-desmethylmetoprolol (ODMTP), 2-OH-carbamazepine (2-OH-CBZ) and 10,11-epoxy carbamazepine (epoCBZ) were purchased from TRC (Toronto Research Chemicals Inc., Ontario, Canada). Verapamil (VPM) was obtained from the European Pharmacopoeia (EP). Desmethyl-sulfamethoxazole (des-SMX) was 
kindly provided by Dr.Tobias Licha, from the Geoscience Centre of the University of Göttingen. Isotopically labelled compounds, used as internal standards were purchased from SigmaAldrich (atenolol- $d_{7}$, fluoxetine- $d_{5}$ ), TRC (verapamil- $d_{6}$, diclofenac- $d_{4}$, 4'-OH-diclofenac- $d_{4}$, sulfamethoxazole- $d_{4}, \quad N^{4}$-acetylsulfapyridine- $d_{4}, \quad N$, L-O-desmethylvenlafaxine- $d_{4} \quad$ and acetaminophen- $d_{4}$ ), Cerilliant (Texas, U.S.A.) (diazepam- $d_{5}$ ) and from CDN isotopes (Quebec, Canada) (carbamazepine- $d_{10}$ and venlafaxine- $d_{6}$ ). Stock standard solutions for each of the analytes were prepared in $\mathrm{MeOH}$ at $1 \mathrm{mg} \mathrm{mL}^{-1}$ and stored in the dark at $-2{ }^{\circ} \mathrm{C}$. Standard solutions of the mixtures of all compounds were made at appropriate concentrations and used to prepare the aqueous calibration curve and also to perform the recovery studies. Similarly, stock standard solutions of the internal standards were prepared. Aqueous standard solutions always contained $<0.1 \%$ of $\mathrm{MeOH}$.

\subsection{Sampling}

For the application and final validation of the methodology, a total of 8 samples of surface water, 6 samples of influent and 6 samples of effluent wastewaters were taken.

Twenty-four hours-integrated samples of WWTP influent (6 samples) and effluent waters (6 samples) were taken in non-consecutive days during winter 2012 from the WWTP of the city of Girona (Spain) and during spring 2013 from the WWTP of Platja d'Aro (Spain), considering the hydraulic retention time in both cases. The WWTP of Girona carries out a secondary biological treatment based on conventional activated sludge (CAS) and serves 206000 equivalent inhabitants. The, second WWTP counted with a membrane bioreactor (MBR) and serves 175000 equivalent inhabitants (maximum capacity). Eight surface water samples were also taken: four of them corresponded to a section of the Segre river located upstream of the nearest urban center in a countryside area, and therefore with very low anthropogenic impact, and the other four were taken downstream the discharge of the WWTP of Girona, in the Ter river. All the different water matrices were collected in amber polyethylene terephthalate (PET) bottles and transported to the laboratory under cooled conditions $\left(4^{\circ} \mathrm{C}\right)$. Upon reception, samples were filtered through $0.45 \mu \mathrm{m}$ Nylon filters (Whatman, Maidstone, UK) to eliminate suspended solid matter and then kept at $-18{ }^{\circ} \mathrm{C}$ until analysis, which was always carried out within $48 \mathrm{~h}$ of collection to avoid degradation. All the analyses were carried out in triplicates.

\subsection{Analytical Methodologymethodology}


Fully automated on-line pre-concentration of samples, aqueous standards and operational blanks was performed using a Thermo Scientific EQuan ${ }^{\mathrm{TM}}$ system consisting of two quaternary pumps: a loading pump (Accela ${ }^{\mathrm{TM}} 600$ pump) and an elution pump (Accela 1250 pump) both of Thermo Scientific (Franklin, MA, US). Two LC columns were used, the first for pre-concentration of the sample and the second for chromatographic separation. A 6-port divert valve was programmed by data system to control the loading and eluting of both columns (see Figure S1 in Supplementary Information (SI)). A Thermo Scientific Hypersil Gold ${ }^{\mathrm{TM}}$ $(50 \times 2.1 \mathrm{~mm}, 1.9 \mu \mathrm{m}$ particle size) was used as a separation column. The flow rate for the

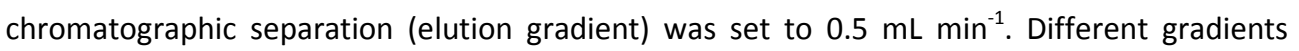
were evaluated for each type of water matrix, depending on the volume of the sample, the transfer time of the sample from the loop to the pre-concentration column and eventually on the elution time to the analytical column.

\subsubsection{UHPLC-MS ${ }^{2}$ analysis}

$\mathrm{MS}^{2}$ analyses were carried out on a TSQ Vantage triple quadrupole (QqQ) mass spectrometer (Thermo Scientific, Franklin, MA, US), equipped with an ESI turbo spray ionization source. The optimization of the $\mathrm{MS}^{2}$ experimental conditions was performed first by syringe infusion and afterwards by on-column injection of standard solutions of the individual compounds at $1 \mu \mathrm{g} \mathrm{mL} \mathrm{m}^{-1}$. Identification of the precursor ions was performed in the full scan mode by recording mass spectra from $\mathrm{m} / \mathrm{z} 50$ to 500 . The target compounds were analyzed in both $\mathrm{PI}$ and $\mathrm{NI}$ modes simultaneously, and the resulting operating parameters were as follows for both (NI/PI): spray voltage $3000 / 4000 \mathrm{~V}$, sheath gas pressure $30\left(\mathrm{~N}^{2}\right)$, auxiliary gas pressure $10\left(\mathrm{~N}^{2}\right)$, ion sweep gas pressure $0\left(\mathrm{~N}^{2}\right)$, vaporizer temperature, $200{ }^{\circ} \mathrm{C}$ and capillary temperature, $250{ }^{\circ} \mathrm{C}$. Analyses were performed in the selected reaction monitoring (SRM), recording two SRM transitions per compound, one for quantitation and the other for positive confirmation; time-specific SRM windows were adjusted to the chromatographic retention times (RTs) of each target compound to improve the sensitivity performance of the QqQ. The optimized $\mathrm{MS}^{2}$ parameters for SRM analysis are given in Table 1.

\section{RESULTSANDDISCUSSIONResults and discussion}




\subsubsection{Mobile phase optimization}

The simultaneous analysis of PhACs and metabolites which ionize in both $\mathrm{PI}$ and $\mathrm{NI}$ made the selection of the appropriate mobile phase crucial. Consequently, different combinations of UHPLC water, $\mathrm{ACN}$ and $\mathrm{MeOH}$, with the corresponding modifiers were tested. The use of acidified aqueous mobile phases is commonly used in PI mode, as it improves the ionization efficiency of basic compounds. Results showed that whereas UHPLC grade water (ammonium formate-formic acid buffer at $1 \mathrm{mM}$ )/MeOH resulted in better peak shapes and intensities for the PI compounds, UHPLC grade water/ACN with no buffer addition was the optimum combination to obtain the best chromatography and analyte response for the $\mathrm{NI}$ compounds. In order to meet a compromise, UHPLC water with $0.01 \%$ of $\mathrm{HCOOH}$ and $\mathrm{ACN}$ was selected eventually. The optimum temperature for analysis was set at $30^{\circ} \mathrm{C}$. A summary of the optimized LC gradients is given in Table S1 (SI).

\subsubsection{Pre-concentration column}

Three different types of pre-concentration columns from Thermo Scientific were used in order to get the best retention and extraction of the target analytes: a Hypersil GOLD ${ }^{\mathrm{TM}}$ Aqua, specially indicated for the retention of very polar compounds and to work with high flow of aqueous mobile phases; a Hypersil Hypercarb $(20 \times 2.1 \mathrm{~mm} 12 \mu \mathrm{m})$, also highly indicated for the retention of polar and structurally related compounds, and a Hypersil GOLD ${ }^{\mathrm{TM}}$ PFP, modified to retain mixtures of halogenated compounds but also non-halogenated polar aromatic compounds. Figure 1a shows the recoveries obtained for each of the columns, working with water concentrations of $100 \mathrm{ng} \mathrm{L}^{-1}$. Both the chromatographic peak area and the peak shape were considered, as peak tailings and shoulders could lead to false high recoveries. 


\subsubsection{Sample $\mathrm{pH}$ and $\mathrm{ACN}$ addition}

Once the Equan ${ }^{\mathrm{TM}}$ column was selected, the main goal was to further improve the retention of the target analytes and thus increase the efficiency. Samples of $1 \mathrm{~mL}$ of UHPLC water, spiked with the mixture of all the compounds at $100 \mathrm{ng} \mathrm{L}^{-1}$, were analyzed varying their $\mathrm{pH}$ values from 3 to 11 . The retention of the different compounds at different $\mathrm{pH}$ values was compared to their retention in the original sample (UHPLC water, pH: 8.1) (see Figure S2-a in $\mathrm{SI})$. For the majority of the target compounds, the chromatographic signal decreased significantly at acidic $\mathrm{pH}$, with the exception of VPM, norVPM and 4-nitro-SMX. Neutral pH yielded slightly lower signals than $\mathrm{pH} 8$, and a more basic $\mathrm{pH}$ generally decreased the signal. Eventually, the most intense peaks were obtained when the $\mathrm{pH}$ in the water sample was unchanged $(\mathrm{pH} 8.1)$

The addition of organic solvent ( $A C N)$ to the sample was then evaluated to improve the aggregation of the analytes and the peak shape, as reported previously [30]. ACN was added at a $2 \%, 5 \%$ and $10 \%$ proportion in the sample (see Figure $\mathbf{S} 2-\mathrm{b}$ ). No improvement was observed with a few exceptions (the signal of 4 of the compounds, DCF, desVPM, FXT and 4-nitro-SMX was enhanced by the addition of $5 \%$ ACN). Signals were generally lower, and proportions of $5 \%$ ACN or higher disrupted the signals, creating tailing or splitting the chromatographic peaks. Eventually, no ACN was added to the samples.

\subsection{4. $\mathrm{Na}_{2} E D T A$ addition}

In order to further improve the column retention efficiency, the addition of the chelating agent $\mathrm{Na}_{2}$ EDTA was also evaluated. The addition of this and other chelating agents is generally recommended in multi-residue methodologies, as they complex soluble metals and multivalent cations present in the different water matrices, especially in those with high organic loads [33], favoring the enhancement in the chromatographic signal as well as improving the peak shape and sharpness. Different volumes of a solution $0.1 \mathrm{M}$ of $\mathrm{Na}_{2} \mathrm{EDTA}$ 
were added to real matrix samples to achieve final concentrations of $1 \%, 3 \%$ and $5 \%$. As observed in Figure S3 in SI, peak intensities increased for the majority of the compounds in the three water matrices along with the percentage of $\mathrm{Na}_{2}$ EDTA, indicating a better compound retention in the pre-concentration column. For those analytes that did not show any increase in the signal at any addition level of $\mathrm{Na}_{2}$ EDTA, especially in effluent samples, the decrease in the peak area was generally not higher than 5-10\%. Only 3-OH-ACM and FXT decreased their peak intensities markedly in influent wastewater samples. The signal improvement was more evident for river water samples, in which the increase of the peak area was observed for all the compounds (except for SPY and SMZ). The signal of the sulfonamide SMX was also remarkably improved in effluent and influent wastewaters. Figure S4 shows an example of signal improvement for SMX in influent and effluent wastewater. Finally, a volume corresponding to $5 \%$ of $\mathrm{Na}_{2}$ EDTA was selected.

\subsubsection{Sample volume (transfer time and elution time) and gradient} optimization

Sample load volume was optimized for the different water matrices. Real matrix volumes ranging from 1 to $5 \mathrm{~mL}$ were tested and different sample injection loops were used accordingly (1, 2 and $5 \mathrm{~mL})$. In LC-LC methodologies, two different flow rates should be considered: the first from the loading pump which pushes the sample from the loop onto the pre-concentration column $\left(\operatorname{Equan}^{\mathrm{TM}}\right)$, and the second from the elution pump, which goes through the analytical column and should be adjusted to obtain the best elution of the analytes from the column into the analyzer. Depending on the sample volume tested, the time required to evacuate the sample from the corresponding loops onto the Equan ${ }^{\mathrm{TM}}$ column (transfer time) was adjusted along with the load flow rate. The flow rate in this load step must be high enough not to let the matrix components to be retained in the Equan ${ }^{\mathrm{TM}}$ column, but not compromising the retention and concentration of the target analytes in it. After the sample loading, the 6-port valve switches and the analytes are transferred from the Equan ${ }^{\text {TM }}$ column onto the analytical column at a lower flow rate. Then the valve switches again and the conventional elution step from the analytical column to the analyzer begins. The elution flow rate was set to $0.5 \mathrm{ml} \mathrm{min}^{-1}$ during the entire gradient; simultaneously during the elution step, the Equan $^{\mathrm{TM}}$ column is cleaned and also preconditioned for the next sample (see Fig 1). The same mobile phases are used through both columns. Final gradients for the analysis of the 
Recovery values for the different volumes tested for each water type are shown in Table S2 (SI), where a goodness range between $75 \%$ and $125 \%$ has been marked. Peak shape and matrix effects were also considered and eventually, a volume of $1 \mathrm{~mL}$ was chosen for influent wastewater, $2 \mathrm{~mL}$ for effluent wastewater and $5 \mathrm{~mL}$ for surface water.

\section{2. $\mathrm{MS}^{2}$ conditions}

MS conditions for a total of 12 PhACs, 20 metabolites and 11 deuterated internal standards were optimized. For 2 of them (DCF and glu-DCF), the best chromatographic responses were obtained working in $\mathrm{NI}$, whereas for the remaining compounds better responses where obtained in $\mathrm{PI}$ mode. In the case of 4-OH-DCF, the same good results were obtained in both $\mathrm{PI}$ and $\mathrm{NI}$ mode. In all cases, $[\mathrm{M}-\mathrm{H}]^{-}$for $\mathrm{NI}$ and $[\mathrm{M}+\mathrm{H}]^{+}$for $\mathrm{PI}$ mode were selected as precursor ions. Some additional pharmaceuticals were considered before the validation of the methodology. Due to its molecular similarity to the sulfonamides evaluated so far, SDZ and its acetylated metabolite acSDZ were included in the methodology scope after the optimization was finished. The same applied for acridine (ACRI), DZP and its metabolite desDZP, with a molecular structure similar to that of CBZ. Metoprolol (MTP) and its three major metabolites were also included at this stage as representative of the $\beta$-blockers, but were only considered in the analysis of wastewaters. As mentioned in section 2.3.2, two SRM transitions between the precursor ion and the two most abundant fragment ions were monitored for each compound, except for the isotopically labeled internal standards, for which only one transition was monitored as they are not found in the environment. Due to the poor fragmentation of the analgesic ACM, only one SRM transition could be registered for it. Following the Council Directive 96/23/EC implementation of 2002 [37] regarding the performance of analytical methods, other identification criteria considered were the chromatographic retention time (RT) of each of the analytes (differences between the RT in the sample and the RT in the standard curve should be within $\pm 2 \%$ ), and the ratio of both SRM transitions abundances, which should be in the range $\pm 20-30 \%$ of the same SRM ratio in the standard curve. Time-specific SRM windows were adjusted to the RTs of each target compound to improve the performance of the QqQ, allowing both the cycle time and the dwell time to be automatically optimized and therefore gaining sensitivity and accuracy. 


\subsection{Method Performanceperformance}

\subsubsection{Matrix effects}

Different approaches are commonly used to decrease the amount of matrix components before LC-MS ${ }^{2}$ analyses, such as the improvement of the clean-up of the extracts or the optimization of the chromatographic gradient and flow [31]. The dilution of samples also decreases the amount of organic load entering the analyzer and can improve the signal, although it can reduce the sensitivity of the method considerably. Another parameter to be considered is the sweep gas of the interface, which helps to tackle with matrix compounds during the ionization, especially for dirty matrices such as influent or effluent wastewater samples. Undoubtedly the use of isotopically labeled internal standards is the most versatile procedure to compensate matrix effects (ME) during quantification, despite their usually high prices and the limited commercial availability for some of them.

Considering potential ME, quantification was carried out following the internal standard calibration approach. Eight point calibration curves $\left(0.01-500 \mathrm{ng} \mathrm{L}^{-1}\right)$ were built for each of the analytes, following a least square linear regression analysis. Linearity was given as the regression coefficient $\left(r^{2}\right)$ and was always equal or above 0.999. The corresponding deuterated compounds used as internal standards were added to all the samples and standard solutions for the calibration curve at a concentration of $500 \mathrm{ng} \mathrm{L}^{-1}$ right before analysis. Matrix matched calibration curves were also built by means of standard addition for the three water matrices studied. The slopes of the resulting curves were compared to the slopes of the calibration curves built in HPLC water in order to evaluate signal suppression or enhancement during the analysis. ME\% values were calculated following equation [1]:

[1] $M E \%=100 \times\left(1-\frac{\left(\text { Slope }_{\text {std_addition }}\right)}{\text { Slope }_{U_{\text {UPLC_curve }}}}\right)$

where ME\% is the matrix effect measured, slope std_addition $_{\text {is }}$ is the slope of the matrix matched calibration curve, and slope UHPLC_curve $_{\text {is }}$ the slope of the calibration curve built in HPLC water. ME\% values obtained are given in Table 2. As an example, Figure S5 in SI shows the standard calibration curves and the matrix matched calibration curves for effluent wastewater, influent wastewater and surface water for O-desVFX and 2-OH-CBZ. The notorious slope difference observed between the matrix-matched curves and the HPLC-water curves highlighted the signal suppression effect. 
Strong signal suppression ( $>50 \%$ ) was observed in the three types of water but especially in the effluent samples. In comparison, most of the ME\% values remained between $25-50 \%$ for the influent samples, due probably to the small sample volume loaded on the preconcentration column $(1 \mathrm{~mL})$ and the high flow-rate of load, which could reduce considerably the retention of matrix components. Regarding surface waters, despite the loaded volume of 5 $\mathrm{mL}$, the lower organic load of this water matrix together with the shorter elution time between both columns could explain the lower ME\% values obtained.

The difference in the slopes decreased considerably with the addition of the deuterated compounds, compensating the matrix effects during quantification for most of the target analytes. It should be taken into account that environmental waters are not homogeneous, and neither are the matrix effects that may happen in the ESI source. This means that the ME\% values given in Table 2 should be considered as indicators of the signal suppression or enhancement for the studied matrices, as this ME\% could differ in each individual sample.

\subsubsection{Method Validationvalidation}

After optimization, the analytical method developed was evaluated in terms of linearity, repeatability, accuracy, selectivity and sensitivity. As mentioned in the previous section, quantification was performed based on peak areas and by the internal standard calibration approach. Concentrations were estimated for the most abundant SRM transition selected. Eight point calibration curves were built at concentrations ranging from 0.1 to $500 \mathrm{ng}$ $\mathrm{L}^{-1}$; correlation coefficients were equal or higher than 0.999 for all the compounds. Accuracy was given as relative recovery values (R\%) of each compound in each water matrix at 3 different spike levels. Results are given in Table 3, and were higher than $75 \%$ with only a few exceptions with low recoveries (SDZ in influent R\% values, DZP in surface water R\% values). On the contrary, high R\% for some compounds such as ACM were also registered, which could be attributed to an operational mistake during the off-line standards analyses. Sensitivity is one of the method parameters enhanced when performing on-line SPE analysis. Despite the low sample volumes required, it has been proved that sensitivity is not affected but, on the contrary, improved considerably. Table 4 shows method limits of detection (MLOD) and quantification (MLOQ) for each of the three water matrices, calculated as the minimum detectable amount of analyte with a signal-to-noise ratio of 3 and 10, respectively. MLOD 
values were in the range of $0.1 \mathrm{ng} \mathrm{L}^{-1}$ (gluDCF-ACRI, norDZP) to $42.4 \mathrm{ng} \mathrm{L}^{-1}$ (des-SMX) for WWTP influent, 0.03-26.4 $\mathrm{ng} \mathrm{L}^{-1}$ (ACRI and ACM, respectively) for WWTP effluent and 0.01-73.2 $\mathrm{ng} \mathrm{L}^{-1}$ for surface water samples (VPM and 3-OH-ACM).

The precision of the method was evaluated by analyzing five consecutive times the corresponding water matrices spiked with a standard mixture of the analytes at concentrations ranging from 50 to $1000 \mathrm{ng} \mathrm{L}^{-1}$. The values of the estimated relative standard deviations (RSD\%) were below $5-10 \%$ for the majority of the analytes.

\subsection{Application to environmental samples}

The new methodology was applied to the determination of the target PhACs, metabolites and TPs in the three water matrices studied. As mentioned in section 2.2, 8 wastewater influent and effluent samples were taken in two different WWTPS. Results are shown in Table 5: samples 1-2 corresponded to a WWTP with CAS treatment and samples 3-6 corresponded to a WWTP with a MBR as secondary treatment. In both WWTPs, influent and effluents were taken as 24-hours integrated samples.

The highest concentrations in influent wastewater corresponded to ACM, with concentrations up to $40.2 \mu \mathrm{g} \mathrm{L}^{-1}$. Similar results for this anti-inflammatory have been detected in previous studies [33]. Annual consumption of ACM is estimated in 700-1400 tons per year in Spain [38], and it is usually amongst the PhACs detected at highest levels [8, 39]. It should be highlighted that the metabolite 4-OH-DCF was present in all the influent samples at concentrations ranging between $53 \mu \mathrm{g} \mathrm{L}^{-1}$ and $366 \mu \mathrm{g} \mathrm{L}^{-1}$, with an average concentration ratio 4-OH-DCF/DCF of 0.6. These values are in accordance to the human metabolic excretion rate of DCF. A $60 \%$ of the oral dose of DCF is excreted in the urine as metabolites and conjugates, and $4-\mathrm{OH}-\mathrm{DCF}$ represents the $30 \%$ of the metabolic excretion rate of DCF [40]. In a previous study, a higher ratio (2.2) for this two compounds was found in influent wastewaters in Catalonia (Spain). The ratio O-desVFX/VFX (1.9-2.6) is in accordance with published data [41, 42] but was lower than those reported by other authors $[43,44]$. Regarding the $\beta$-blocker MTP and its metabolites, MTPA/MTP ratios in the influent ranged between $60-80$, and are in accordance with the metabolic excretion rates of these compounds $(60-65 \%$ of the MTP is excreted as MTPA and only a $3-10 \%$ is excreted in its original form) [45]. Concentrations of MTPA in the MBR effluents were higher than those detected in the influent in 3 of the 4 paired samples, with negative elimination rates ranging from $-48.8 \%$ (I6-E6) to $-171 \%$ (I3-E3). These results could indicate the formation of this compound as biodegradation product of the parent 
compound MTP; however, similarly to the metabolite, this $\beta$-blocker was unaltered during treatment, and similarly to MTPA, concentrations were higher in the effluent samples. Rubirola et al. also reported a similar behavior for MTPA and observed a concentration for this metabolite 10 times higher in effluent than in the influent wastewater of 2 urban WWTPS (CAS and MBR). In this study, these high concentrations were attributed to the generation of MTPA from atenolol, the major $\beta$-blocker present in influent wastewaters (up to 2 orders of magnitude higher than MTP) [46]. Radjenovic et al. [46] demonstrated that MTPA was also a primary degradation product for atenolol in MBR-sludge batch experiments, in which MTPA was detected simultaneously to the immediate degradation of atenolol and reached a $40 \%$ of the initial spiked concentration of atenolol after only 1 day. Despite atenolol is out of the scope of this work, atenolol has been frequently detected in MBR influent wastewaters [8, 47]. Higher levels of the metabolites acSPY and norFXT compared to their corresponding parent compounds were also found in the influent samples.

Concentrations were significantly lower in the wastewater effluent samples; ACM was efficiently removed after MBR treatment, whereas it was still present in E1 and E2 after CAS treatment, at levels ranging from 0.47 to $0.53 \mu \mathrm{g} \mathrm{L}^{-1}$. Concentrations for $4-\mathrm{OH}-\mathrm{DCF}$ in the effluent were lower than in the influent, whereas those for DCF did not seem to vary significantly. This was reflected in the concentration ratio for both, which decreased to 0.4. Stülten et al. estimated a ratio of 0.7 in effluent wastewaters in Germany [48] , whereas Osorio et al. estimated even higher ratios (2.5-3) [49]. Furthermore, adDCF was detected in both CAS effluents, despite at low concentration (0.9-1.2 $\left.\mathrm{ng} \mathrm{L}^{-1}\right)$, whereas it was not present in the corresponding influent samples and so it can be considered as a likely degradation TP of either DCF or 4-OH-DCF. WWTPs designs and operational parameters may account for these differences. VFX and its two desmethylated metabolites were detected in all the effluent samples. CAS treatment seemed to be more efficient in the elimination of the metabolites than MBR, as the concentrations in the MBR effluents were in the same range that those detected in the influents. Regarding VFX, it is worth mentioning that its concentration in the effluent was higher or basically the same as in the influent samples taken from the WWTP with the CAS treatment, and in two of the four samples taken in the MBR. These results are in accordance with previous studies $[41,44]$. This event has been discussed in different studies for other compounds (i.e. SMX) and it is usually attributed to the presence of conjugate compounds, that may not be included within the scope of the study, which revert back to their original compound during treatment $[50,51]$. This happened also for norFXT and for the TP adDCF, which was only detected in the effluent, fact that could be explained if adDCF was a 
potential intermediate product of DCF degradation (with elimination rates of $70-76 \%$ ). However, further studies should be carried out in order to confirm this possibility.

As expected, very few target compounds at low concentrations were detected in the water samples taken in a pristine river. CBZ was detected in the four samples, (2.4-4.1 $\left.\mathrm{ng} \mathrm{L}^{-1}\right)$. None of its corresponding metabolites or TPs was detected. VFX was not detected in any of these samples, but its main metabolite O-desVFX was detected in all of them, despite of low concentrations (1.57-2.35 $\mathrm{ng} \mathrm{L}^{-1}$ ). Non-point sources, such as residual water discharges from little villages upstream with no current wastewater treatment, high resilience to degradation of $\mathrm{CBZ}$ or the high consumption of the targeted drugs could explain the occurrence of these compounds in river waters with a low anthropogenic impact. In contrast, concentrations of target pollutants, both parent compounds and metabolites and TPs, in the second river studied, where samples were taken downstream of a WWTP were noticeably higher. For some of the compounds such as ACM, DCF, CBZ, VFX, their metabolites O-desVFX, N-desVFX and acSPY, concentration levels were comparable to those detected in some of the effluent samples studied. For instance, ACM was present at high concentrations, in the range of 287.3$577.9 \mathrm{ng} \mathrm{L}^{-1}$, and similar concentrations had already been detected in different samples taken in the Ebro River basin in a work by López-Serna et al. [10]. Altough river and effluent data are independent (river and effluent samples taken were not directly linked, as they were sampled in different year seasons and in different locations) the concentration ranges obtained help to fathom out the current status of receiving river waters, highlighting the ubiquity of the PhACs studied once discharged and increasing the concern regarding their potential ecotoxicity. DCF and CBZ and their hydroxylated metabolites were present in the four samples, with concentrations generally one order of magnitude higher for the parent compound. VFX and its two metabolites were also present in all the samples, but in this case, however, the concentration of O-desVFX was higher than that of VFX except for one sample.

In conclusion, metabolites and TPs are present at low concentrations in surface water, even in areas with low impact from WWTP discharges. These results highlight and reinforce the need of including metabolites and TPs in future screening and environmental studies. 


\section{GONCLUSIONSCOnclusions}

The analytical methodology presented in this work, based on LC-LC-ESI-MS ${ }^{2}$, has been proved to be a highly selective, sensitive and accurate for the detection of selected pharmaceutical and their corresponding metabolites and TPs in wastewaters and surface waters. It allows for a very efficient pre-concentration and clean-up of the samples, requiring a minimum manipulation and pretreatment (only the filtration step) and also a very low volume of the sample. The new methodology has allowed simultaneous analysis in both $\mathrm{NI}$ and PI mode without compromising the sensitivity of the analysis, obtaining LODs in the low $\mathrm{ng} \mathrm{L}^{-1}$ for most of the compounds. Matrix effects were also reduced by means of LC-LC clean up.

Results have demonstrated the widespread presence of the different metabolites and TPs in all the water matrices studied, at similar or even higher levels than the corresponding parent compounds. The presence of the TPs O-desVFX and N-desVFX in all the analyzed samples, in the case of O-desVFX generally at concentrations higher than those of VFX, should be emphasized. Similar results were obtained for acSPY and for desFXT in wastewaters. The TP adDCF was detected only in effluent wastewaters, suggesting the formation of this product during wastewater treatment. These results reinforce the need of including metabolites and TPs within the scope of future monitoring studies, as these data lead to a better understanding of biodegradation and attenuation processes of these PhaCs once discharged in the environment.

\section{ACKNOWLEDGMENTSAcknowledgments}

This study has been supported by the Generalitat de Catalunya (Consolidated Research Group: Catalan Institute for water Research 2014 SGR 291), by the Spanish Ministry of Economy and Competitiveness through the SCARCE project (Consolider-Ingenio 2010 CSD2009-00065) and by the European Union through the European Regional Development Fund (ERDF). MJ. García acknowledges the Beatriu de Pinos program (2014 BP-A 00245); Sara Rodriguez-Mozaz acknowledges the Ramon y Cajal program (RYC-2014-16707).

MJ. García would like to thank the support of C. Martins, S. Insa and M. Villagrasa during the development of the methodology, of $\mathrm{M}$. Llorca for her uninterested help with the set-up of the on-line configuration and L. Ferrando-Climent, M. Stefani and J. Mamo for her help during the sampling campaign. 
[1] K. Kümmerer, J. Environ. Manage. 90(8) (2009) 2354-2366.

[2] D. Fatta-Kassinos, S. Meric, A. Nikolaou, Anal. Bioanal. Chem. 399(1) (2010) 251-275.

[3] M. Gros, M. Petrovic, A. Ginebreda, D. Barceló, Environ. Int. 36(1) (2010) 15-26.

[4] P. Verlicchi, A. Galletti, M. Petrovic, D. Barceló, J. Hydrol. 389(3-4) (2010) 416-428.

[5] M. Clara, B. Strenn, M. Ausserleitner, N. Kreuzinger, Water Sci. Technol. 2004, pp. 29-36.

[6] S.C. Monteiro, A.B. Boxall, Rev. Environ. Contam. Toxicol. 202 (2010) 53-154.

[7] D. Fatta-Kassinos, S. Meric, A. Nikolaou, Anal. Bioanal. Chem. 399(1) (2011) 251-275.

[8] M. Gros, S. Rodríguez-Mozaz, D. Barceló, J. Chromatogr. A 1248 (2012) 104-121.

[9] R. López-Serna, S. Pérez, A. Ginebreda, M. Petrović, D. Barceló, Talanta 83(2) (2010) 410424.

[10] R. López-Serna, M. Petrovic, D. Barceló, Sci. Total Environ. 440 (2012) 280-289.

[11] M. Petrović, B. Škrbić, J. Živančev, L. Ferrando-Climent, D. Barcelo, Sci. Total Environ. 468469 (2013) 415-428.

[12] M. Cleuvers, Ecotox. Environ. Safe. 59(3) (2004) 309-315.

[13] T. Schulze, S. Weiss, E. Schymanski, P.C. von der Ohe, M. Schmitt-Jansen, R. Altenburger, G. Streck, W. Brack, Environ. Pollut.158(5) (2010) 1461-1466.

[14] M. Isidori, M. Lavorgna, A. Nardelli, L. Pascarella, A. Parrella, , Sci. Total Environ. 346(1-3) (2005) 87-98.

[15] D. Fatta-Kassinos, M.I. Vasquez, K. Kümmerer, Chemosphere 85(5) (2011) 693-709.

[16] E. Donner, T. Kosjek, S. Qualmann, K.O. Kusk, E. Heath, D.M. Revitt, A. Ledin, H.R. Andersen, Sci. Total Environ. 443 (2013) 870-876.

[17] Commission Directive 93/67/EEC

[18] M. García-Galán, S. González Blanco, R. López Roldán, S. Díaz-Cruz, D. Barceló, , Sci. Total Environ. 437 (2012) 403-412.,

[19] M.C. Dodd, H.P. Kohler, U. von Gunten, Environ. Sci. Technol. 43(7) (2009) 2498-504.

[20] M. Majewsky, D. Wagner, M. Delay, S. Bräse, V. Yargeau, H. Horn, Chemical Res. Toxicol.27(10) (2014) 1821-1828. 
[21] M.J. García-Galán, M.S. Díaz-Cruz, D. Barceló, Talanta 81(1-2) (2010) 355-366.

[22] T. Hata, S. Kawai, H. Okamura, T. Nishida, Biodegradation 21(5) (2010) 681-689.

[23] E. Marco-Urrea, M. Pérez-Trujillo, C. Cruz-Morato, G. Caminal, T. Vicent, J. Hazard. Mater.176(1-3) (2010) 836-842.

[24] L.A. Pérez-Estrada, S. Malato, W. Gernjak, A. Agüera, E.M. Thurman, I. Ferrer, A.R. Fernández-Alba, Environ. Sci. Technol.39(21) (2005) 8300-8306.

[25] A. Jelic, C. Cruz-Morató, E. Marco-Urrea, M. Sarrà, S. Perez, T. Vicent, M. Petrovic, D. Barceló, Water Res. 46(4) (2012) 955-964.

[26] F. Martínez, M.J. López-Muñoz, J. Aguado, J.A. Melero, J. Arsuaga, A. Sotto, R. Molina, Y. Segura, M.I. Pariente, A. Revilla, L. Cerro, G. Carenas, Water Res. 47(15) (2013) 5647-5658.

[27] M. Gros, M. Petrović, D. Barceló, Anal.Bioanal. Chem. 386(4) (2006) 941-952.

[28] A. Göbel, C.S. McArdell, M.J.F. Suter, W. Giger, Anal. Chem. 76(16) (2004) 4756-4764.

[29] S. Rodriguez-Mozaz, M.J. Lopez de Alda, D. Barceló, J. Chromatogr. A 1152(1-2) (2007) 97115.

[30] M. Gorga, M. Petrovic, D. Barcelo, J. Chromatogr. A 1295(21) (2013) 57-66.

[31] J.-P. Antignac, K. de Wasch, F. Monteau, H. De Brabander, F.o. Andre, B. Le Bizec, Anal. Chim. Acta 529 (2005) 129-136.

[32] M.J. García-Galán, S. Díaz-Cruz, D. Barceló, J. Chromatogr. A 1275(0) (2013) 32-40.

[33] M. Gros, S. Rodriguez-Mozaz, D. Barcelo, J. Chromatogr. A J. Chromatogr. A 1292(31) (2013) 173-88.

[34] J. Wang, P.R. Gardinali, Chemosphere 107 (2014) 65-73.

[35] E. Gracia-Lor, M. Ibáñez, T. Zamora, J. Sancho, F. Hernández, Environ. Sci. Pollut. Res. 21(8) (2014) 5496-5510.

[36] N.V. Heuett, S.R. Batchu, P.R. Gardinali, J. Hazard. Mater. 282 (2015) 41-50.

[37] COMMISSION DECISION of 12 August 2002. Official Journal of the European Communities (2002).

[38] S. Ortiz de García, G. Pinto Pinto, P. García Encina, R. Irusta Mata, Sci. Total Environ. 444 (2013) 451-465.

[39] M. Pedrouzo, F. Borrull, E. Pocurull, R.M. Marcé, Water Air Soil Poll. 217(1) (2010) 267281. 
[40] H. Stierlin, J.W. Faigle, A. Sallmann, W. Kung, W.J. Richter, H.P. Kriemler, K.O. Alt, T. Winkler, Xenobiotica 9(10) (1979) 601-610.

[41] M.P. Schlüsener, P. Hardenbicker, E. Nilson, M. Schulz, C. Viergutz, T.A. Ternes, Environ. Pollut.196 (2015) 247-256.

[42] A. Lajeunesse, C. Gagnon, S. SauvÃ@, Anal. Chem. 80(14) (2008) 5325-5333.

[43] P. Rúa-Gómez, W. Püttmann, Environ. Sci. Pollut. Res. 19(3) (2012) 689-699.

[44] G. Gasser, I. Pankratov, S. Elhanany, P. Werner, J. Gun, F. Gelman, O. Lev, Chemosphere 88(1) (2012) 98-105.

[45] S. Kern, R. Baumgartner, D.E. Helbling, J. Hollender, H. Singer, M.J. Loos, R.P. Schwarzenbach, K. Fenner, J. Environ. Monitor.12(11) (2010) 2100-2111.

[46] J. Radjenović, S. Pérez, M. Petrović, D. Barceló, J. Chromatogr. A 1210(2) (2008) 142-153.

[47] M.S. Kostich, A.L. Batt, J.M. Lazorchak, Environ. Pollut. 184 (2014) 354-359.

[48] D. Stülten, S. Zühlke, M. Lamshöft, M. Spiteller, Occurrence of diclofenac and selected metabolites in sewage effluents, Sci. Total Environ. 405(1-3) (2008) 310-316.

[49] V. Osorio, M. Imbert-Bouchard, B. Zonja, J.-L. Abad, S. Pérez, D. Barceló, J. Chromatogr. A 1347 (2014) 63-71.

[50] M.J. García-Galán, T. Frömel, J. Müller, M. Peschka, T. Knepper, S. Dïaz-Cruz, D. Barceló, Anal. Bioanal. Chem. 402(9) (2012) 2885-2896.

[51] A. Göbel, C.S. McArdell, A. Joss, H. Siegrist, W. Giger, Sci. Total Environ. 372(2-3) (2007) 361-371. 


\title{
MULTIRESIDUE TRACE ANALYSIS OF PHARMACEUTICALS, THEIR HUMAN METABOLITES AND TRANSFORMATION PRODUCTS BY FULLY AUTOMATED ON-LINE SOLID-PHASE EXTRACTION-LIQUID CHROMATOGRAPHY-TANDEM MASS SPECTROMETRY
}

\author{
Ma Jesús García-Galán ${ }^{1,2^{*}}$, Mira Petrovic ${ }^{2}$, Sara Rodríguez-Mozaz ${ }^{2}$, Damià Barceló ${ }^{2}$ \\ 1. LEQUIA, Institute of the Environment, University of Girona, Campus Montilivi, E-17071, Girona, Spain \\ 2. ICRA, Catalan Institute for Water Research, Emili Grahit 101, E-17003 Girona, Spain
}

\begin{abstract}
A novel, fully automated analytical methodology based on dual column liquid chromatography coupled to tandem mass spectrometry (LC-LC-MS ${ }^{2}$ ) has been developed and validated for the analysis of 12 pharmaceuticals and 20 metabolites and transformation products in different types of water (influent and effluent wastewaters and surface water). Two LC columns were used - one for pre-concentration of the sample and the second for separation and analysis - so that water samples were injected directly in the chromatographic system. Besides the many advantages of the methodology, such as minimization of the sample volume required and its manipulation, both compounds that ionize in positive and negative mode could be analyzed simultaneously without compromising the sensitivity. A comparative study of different mobile phases, gradients and LC pre-concentration columns was carried out to obtain the best analytical performance. Limits of detection (MLODs) achieved were in the low $\mathrm{ng} \mathrm{L}^{-1}$ range for all the compounds. The method was successfully applied to study the presence of the target analytes in different wastewater and surface water samples collected near the city of Girona (Catalonia, Spain). Data on the environmental presence and fate of pharmaceutical metabolites and TPs is still scarce, highlighting the relevance of the developed methodology.
\end{abstract}

Keywords: LC-LC analysis, metabolites, transformation products, environmental waters. 


\section{Introduction}

Thousands of tons of different classes of pharmaceutical active compounds (PhACs) are used on a regular basis in human and veterinary medicine worldwide. After their usage and excretion, it is highly probable that both the metabolites and the unchanged parent drug enter the environment [1]. Due to their physical-chemical properties, PhACs are generally hardly biodegradable and only partially removed by physical and standard biological treatment processes (conventional active sludge treatment, (CAS)) in wastewater treatment plants (WWTPs), and could also remain biologically active for long periods [2]. Consequently, several studies concluded that effluents from urban WWTPs should be considered one of the main entrance pathways of PhACs into the environment and therefore partly responsible for surface and marine water contamination [2-4]. The presence of PhACs in all kind of environmental waters has been widely documented during the last decades, at concentrations ranging from $n g L^{-1}$ to $\mu \mathrm{g} \mathrm{L}^{-1}$ [7-11]. Although information is still scarce on the ecotoxicity derived of PhACs under real environmental conditions, it is not expected that these concentrations levels for individual compounds could pose an acute risk. However, the combined effect of a mixture of compounds, sharing or not a common mechanism of action could be substantial [12]. Furthermore, the coexistence of the parent drugs with their human metabolites and transformation products (TPs) could also lead to additive, antagonistic and/or synergetic effects which are hard to predict and should be investigated. For instance, a photodegradation TP of DCF has proved to be phytotoxic against certain species of green algae [13], and the assessment of the ecotoxicity of other photoproducts of DCF and naproxen has provided the evidence that acute and chronic toxicity can be greater for these photoproducts than for the parent compounds $[14,15]$. Donner et al. [16] demonstrated that UV photoproducts of CBZ, acridine and acridone ( $A C R I, A C R O$ ), were more toxic to certain aquatic organisms than the parent compound. Effective concentration values $\left(E C_{50}\right)$ obtained after $15 \mathrm{~min}$ exposure for the antibiotic sulfapyridine (SPY) and its acetylated metabolite, $\mathrm{N}^{4}$-acetylsulfapyridine (acSPY), demonstrated that the marine bacteria Vibrio fischerii was more sensitive to the presence of the metabolite than to the original drug, and according to the European Directive 93/67/EEC [17], acSPY could be categorized as toxic [18]. On the other hand, it has been demonstrated that antimicrobial activity of several antibiotics is fully eliminated after advanced treatments such as ozonation [19], but other environmental degradative processes may not be so efficient against the bioactivity of these micropollutants. Majewsky et al. demonstrated that TPs of 
sulfamethoxazole (SMX) modified in the para (amino) group, such as 4-hydroxy-SMX or 4-nitroVibrio fischerii, and that these effects were additive [20].

Only recently, the environmental presence of human metabolites and TPs of PhACs has started to be considered within the scope of monitoring studies, and eventually regarded as potential elements of risk $[7,10,21]$. During treatment in the WWTP or once released onto the environment, PhACs (and their metabolites) can undergo biotic and abiotic transformation processes (microbial degradation, hydrolysis, photodegradation, oxidation, etc) yielding a potentially high number of new compounds of unknown elemental composition, stability and potency [7]. Human metabolites and TPs can also be identical; this is the case of 4'-OHdiclofenac (4-OH-DCF) and 5-OH-diclofenac, which account for approximately $22 \%$ of the excreted dose of DCF in the urine, but have also been detected as biodegradation products in DCF removal experiments by white rot fungi and identified also as photodegradation TPs [2224]. The same has been observed for the human metabolites of $\mathrm{CBZ}, 2-\mathrm{OH}$-carbamazepine and 10,11-epoxy-carbamazepine (2-OH-CBZ, epo-CBZ), detected after CBZ treatment with fungi [25] and also after its natural biodegradation in soils [26]. However, in many cases degradation pathways are not identical for PhACs, yielding different TPs.

Nowadays, the challenge for PhACs analysis at environmental levels in water matrices has shifted from reaching enough sensitivity and selectivity for their detection, which is generally accomplished using liquid chromatography followed by tandem mass spectrometry (LC-MS ${ }^{2}$ ) as analytical technique, to the reduction of the time of analysis, manipulation of the samples in a minimum number of steps and a reduced use of solvents. Analytical methodologies capable of detection at environmental levels $\left(\mathrm{pg} \mathrm{L}^{-1}\right)$, usually require a clean-up of the sample and pre-concentration of the target analytes based on solid phase extraction (SPE) off-line; SPE involves a certain number of steps that imply several hours of preparation, requiring also sample volumes of up to $100-1000 \mathrm{~mL}$ to obtain the desired sensitivity and the use of significant amounts of solvents [27, 28]. Taking this into account, on-line preconcentration has become one of the most suitable sample preparation approaches available. Previous works account for the many advantages of on-line SPE procedure, such as minimum sample manipulation by the analyst (lower probability of error), reduced sample volume required, reduced time and solvents used and improved throughput [9, 21, 29]. By means of dual column liquid chromatography switching system (LC-LC), ordinary on-line SPE has also been improved, as only one pre-concentration column is used for all the set of samples, instead of one SPE cartridge per sample [30]. 
Although several analytical methods for the determination of pharmaceuticals and TPs are currently available in the literature, the majority is based on off-line SPE [33-35] and the few works dealing with on-line SPE perform analyses in PI and NI mode separately $[10,36]$. The aim of this work is the development and optimization of a new, fast, robust and highthroughput multi-residue analytical method, based on on-line pre-concentration of the target analytes by means of Equan ${ }^{\mathrm{TM}}$ Direct Injection Technology, which permits simultaneous monitoring in either PI and NI mode in the same chromatographic run of 12 pharmaceuticals and 20 of their metabolites and TPs, in surface and wastewaters. The target PhACs were selected considering both their high consumption rates and environmental relevance (high occurrence in the environment). Metabolites and TPs were selected depending on their commercial availability and also considering the little information available regarding their environmental presence.

\section{Materials and methods}

\subsection{Chemicals and reagents}

HPLC-grade solvents (water, methanol $(\mathrm{MeOH})$, acetone and acetonitrile $(\mathrm{ACN})$ ) and formic acid $(\mathrm{HCOOH})(98-100 \%)$ were supplied by Merck (Darmstadt, Germany) and Thermo Fisher Scientific (Franklin, MA, US). High purity standards (>99\%) of the pharmaceuticals acetaminophen (ACM), sulfamethoxazole (SMX), sulfapyridine (SPY), sulfamethazine (SMZ), venlafaxine (VFX), diazepam (DZP), carbamazepine (CBZ), diclofenac (sodium salt)(DCF), fluoxetine (FXT), metoprolol (MTP) and the metabolites norverapamil (norVPM), norfluoxetine (norFXT) and acridine (ACRI) were purchased from Sigma-Aldrich (St. Louis, MO, USA). High purity standards for the metabolites 4-nitro-sulfamethoxazole (4-nitro-SMX), 4'-hydroxydiclofenac (4-OH-DCF), diclofenac amide (adDCF), diclofenac acyl-B-D-glucuronide (gluDCF), acridone (ACRO), D,L-N-desmethylvenlafaxine (N-desVFX), D,L-O-desmethylvenlafaxine (OdesVFX), $\quad \mathrm{N}^{4}$-acetylsulfapyridine (acSPY), $\quad \mathrm{N}^{4}$-acetylsulfamethazine (acSMZ), $\mathrm{N}^{4}$ acetylsulfamethoxazole (acSMX), desmethyldiazepam (norDZP), 3-OH-acetaminophen (3-OHACM), $\alpha$-hydroxymetoprolol ( $\alpha$-HMTP), metoprolol acid (MTPA), O-desmethylmetoprolol (ODMTP), 2-OH-carbamazepine (2-OH-CBZ) and 10,11-epoxy carbamazepine (epoCBZ) were purchased from TRC (Toronto Research Chemicals Inc., Ontario, Canada). Verapamil (VPM) was obtained from the European Pharmacopoeia (EP). Desmethyl-sulfamethoxazole (des-SMX) was kindly provided by Dr.Tobias Licha, from the Geoscience Centre of the University of Göttingen. Isotopically labelled compounds, used as internal standards were purchased from Sigma- 
Aldrich (atenolol- $d_{7}$, fluoxetine- $d_{5}$ ), TRC (verapamil- $d_{6}$, diclofenac- $d_{4}$, 4'-OH-diclofenac- $d_{4}$,

sulfamethoxazole- $d_{4}, \quad N^{4}$-acetylsulfapyridine- $d_{4}, \quad$ N,L-O-desmethylvenlafaxine- $d_{4} \quad$ and acetaminophen- $d_{4}$ ), Cerilliant (Texas, U.S.A.) (diazepam- $d_{5}$ ) and from CDN isotopes (Quebec, Canada) (carbamazepine- $d_{10}$ and venlafaxine- $d_{6}$ ). Stock standard solutions for each of the analytes were prepared in $\mathrm{MeOH}$ at $1 \mathrm{mg} \mathrm{mL}^{-1}$ and stored in the dark at $-2{ }^{\circ} \mathrm{C}$. Standard solutions of the mixtures of all compounds were made at appropriate concentrations and used to prepare the aqueous calibration curve and also to perform the recovery studies. Similarly, stock standard solutions of the internal standards were prepared. Aqueous standard solutions always contained $<0.1 \%$ of $\mathrm{MeOH}$.

\subsection{Sampling}

For the application and final validation of the methodology, a total of 8 samples of surface water, 6 samples of influent and 6 samples of effluent wastewaters were taken.

Twenty-four hours-integrated samples of WWTP influent (6 samples) and effluent waters (6 samples) were taken in non-consecutive days during winter 2012 from the WWTP of the city of Girona (Spain) and during spring 2013 from the WWTP of Platja d'Aro (Spain), considering the hydraulic retention time in both cases. The WWTP of Girona carries out a secondary biological treatment based on conventional activated sludge (CAS) and serves 206000 equivalent inhabitants. The, second WWTP counted with a membrane bioreactor (MBR) and serves 175000 equivalent inhabitants (maximum capacity). Eight surface water samples were also taken: four of them corresponded to a section of the Segre river located upstream of the nearest urban center in a countryside area, and therefore with very low anthropogenic impact, and the other four were taken downstream the discharge of the WWTP of Girona, in the Ter river. All the different water matrices were collected in amber polyethylene terephthalate (PET) bottles and transported to the laboratory under cooled conditions $\left(4{ }^{\circ} \mathrm{C}\right)$. Upon reception, samples were filtered through $0.45 \mu \mathrm{m}$ Nylon filters (Whatman, Maidstone, UK) to eliminate suspended solid matter and then kept at $-18^{\circ} \mathrm{C}$ until analysis, which was always carried out within $48 \mathrm{~h}$ of collection to avoid degradation. All the analyses were carried out in triplicates.

\subsection{Analytical methodology}

\subsubsection{LC-LC conditions}


Fully automated on-line pre-concentration of samples, aqueous standards and operational blanks was performed using a Thermo Scientific EQuan ${ }^{\mathrm{TM}}$ system consisting of two quaternary pumps: a loading pump (Accela ${ }^{\mathrm{TM}} 600$ pump) and an elution pump (Accela 1250 pump) both of Thermo Scientific (Franklin, MA, US). Two LC columns were used, the first for pre-concentration of the sample and the second for chromatographic separation. A 6-port divert valve was programmed by data system to control the loading and eluting of both columns (see Figure S1 in Supplementary Information (SI)). A Thermo Scientific Hypersil Gold ${ }^{\mathrm{TM}}$ (50×2.1 mm, $1.9 \mu \mathrm{m}$ particle size) was used as a separation column. The flow rate for the chromatographic separation (elution gradient) was set to $0.5 \mathrm{~mL} \mathrm{~min}{ }^{-1}$. Different gradients were evaluated for each type of water matrix, depending on the volume of the sample, the transfer time of the sample from the loop to the pre-concentration column and eventually on the elution time to the analytical column.

\subsubsection{UHPLC-MS ${ }^{2}$ analysis}

$\mathrm{MS}^{2}$ analyses were carried out on a TSQ Vantage triple quadrupole (QqQ) mass spectrometer (Thermo Scientific, Franklin, MA, US), equipped with an ESI turbo spray ionization source. The optimization of the $\mathrm{MS}^{2}$ experimental conditions was performed first by syringe infusion and afterwards by on-column injection of standard solutions of the individual compounds at $1 \mu \mathrm{g} \mathrm{mL}^{-1}$. Identification of the precursor ions was performed in the full scan mode by recording mass spectra from $\mathrm{m} / \mathrm{z} 50$ to 500 . The target compounds were analyzed in both $\mathrm{PI}$ and $\mathrm{NI}$ modes simultaneously, and the resulting operating parameters were as follows for both (NI/PI): spray voltage $3000 / 4000 \mathrm{~V}$, sheath gas pressure $30\left(\mathrm{~N}^{2}\right)$, auxiliary gas pressure $10\left(\mathrm{~N}^{2}\right)$, ion sweep gas pressure $0\left(\mathrm{~N}^{2}\right)$, vaporizer temperature, $200{ }^{\circ} \mathrm{C}$ and capillary temperature, $250{ }^{\circ} \mathrm{C}$. Analyses were performed in the selected reaction monitoring (SRM), recording two SRM transitions per compound, one for quantitation and the other for positive confirmation; time-specific SRM windows were adjusted to the chromatographic retention times (RTs) of each target compound to improve the sensitivity performance of the QqQ. The optimized $\mathrm{MS}^{2}$ parameters for SRM analysis are given in Table 1.

\section{Results and discussion}

\subsection{LC-LC conditions}


The method was firstly optimized using $1 \mathrm{~mL}$ samples of UHPLC water spiked with an appropriate volume of a standard mixture of the analytes in order to have final concentrations in water ranging from 50 to $1000 \mathrm{ng} \mathrm{L}^{-1}$. Recoveries were based on the ratio between the peak areas obtained with the LC-LC-MS² analysis and those obtained from a parallel off-line analysis of a standard mixture of the analytes (same total mass injected in both cases in the QqQ analyzer).

\subsubsection{Mobile phase optimization}

The simultaneous analysis of PhACs and metabolites which ionize in both $\mathrm{PI}$ and $\mathrm{NI}$ made the selection of the appropriate mobile phase crucial. Consequently, different combinations of UHPLC water, $\mathrm{ACN}$ and $\mathrm{MeOH}$, with the corresponding modifiers were tested. The use of acidified aqueous mobile phases is commonly used in PI mode, as it improves the ionization efficiency of basic compounds. Results showed that whereas UHPLC grade water (ammonium formate-formic acid buffer at $1 \mathrm{mM}$ )/MeOH resulted in better peak shapes and intensities for the PI compounds, UHPLC grade water/ACN with no buffer addition was the optimum combination to obtain the best chromatography and analyte response for the $\mathrm{NI}$ compounds. In order to meet a compromise, UHPLC water with $0.01 \%$ of $\mathrm{HCOOH}$ and ACN was selected eventually. The optimum temperature for analysis was set at $30^{\circ} \mathrm{C}$. A summary of the optimized LC gradients is given in Table S1 (SI).

\subsubsection{Pre-concentration column}

Three different types of pre-concentration columns from Thermo Scientific were used in order to get the best retention and extraction of the target analytes: a Hypersil GOLD ${ }^{\mathrm{TM}}$ Aqua, specially indicated for the retention of very polar compounds and to work with high flow of aqueous mobile phases; a Hypersil Hypercarb (20×2.1 mm $12 \mu \mathrm{m})$, also highly indicated for the retention of polar and structurally related compounds, and a Hypersil GOLD ${ }^{T M}$ PFP, modified to retain mixtures of halogenated compounds but also non-halogenated polar aromatic compounds. Figure 1a shows the recoveries obtained for each of the columns, working with water concentrations of $100 \mathrm{ng} \mathrm{L}^{-1}$. Both the chromatographic peak area and the peak shape were considered, as peak tailings and shoulders could lead to false high recoveries.

Both the Hypercarb and the GOLD ${ }^{\mathrm{TM}}$ Aqua column yielded the best recoveries for most of the compounds, but the peak shape was generally better for the GOLD ${ }^{T M}$ Aqua column. As 
an example, Figure $1 \mathrm{~b}$ shows the peak intensities obtained with the three columns for three of the analytes. Eventually, Hypersil GOLD ${ }^{\mathrm{TM}}$ Aqua column $(20 \times 2.1 \mathrm{~mm}, 12 \mu \mathrm{m})$ was chosen for sample pre-concentration.

\subsubsection{Sample $\mathrm{pH}$ and $\mathrm{ACN}$ addition}

Once the Equan ${ }^{T M}$ column was selected, the main goal was to further improve the retention of the target analytes and thus increase the efficiency. Samples of $1 \mathrm{~mL}$ of UHPLC water, spiked with the mixture of all the compounds at $100 \mathrm{ng} \mathrm{L}^{-1}$, were analyzed varying their $\mathrm{pH}$ values from 3 to 11 . The retention of the different compounds at different $\mathrm{pH}$ values was compared to their retention in the original sample (UHPLC water, $\mathrm{pH}: 8.1$ ) (see Figure S2-a in SI). For the majority of the target compounds, the chromatographic signal decreased significantly at acidic $\mathrm{pH}$, with the exception of VPM, norVPM and 4-nitro-SMX. Neutral pH yielded slightly lower signals than $\mathrm{pH} 8$, and a more basic $\mathrm{pH}$ generally decreased the signal. Eventually, the most intense peaks were obtained when the $\mathrm{pH}$ in the water sample was unchanged $(\mathrm{pH} 8.1)$

The addition of organic solvent (ACN) to the sample was then evaluated to improve the aggregation of the analytes and the peak shape, as reported previously [30]. ACN was added at a $2 \%, 5 \%$ and $10 \%$ proportion in the sample (see Figure S2-b). No improvement was observed with a few exceptions (the signal of 4 of the compounds, DCF, desVPM, FXT and 4-nitro-SMX was enhanced by the addition of $5 \%$ ACN). Signals were generally lower, and proportions of $5 \%$ ACN or higher disrupted the signals, creating tailing or splitting the chromatographic peaks. Eventually, no ACN was added to the samples.

\subsection{4. $\mathrm{Na}_{2} E D T A$ addition}

In order to further improve the column retention efficiency, the addition of the chelating agent $\mathrm{Na}_{2}$ EDTA was also evaluated. The addition of this and other chelating agents is generally recommended in multi-residue methodologies, as they complex soluble metals and multivalent cations present in the different water matrices, especially in those with high organic loads [33], favoring the enhancement in the chromatographic signal as well as improving the peak shape and sharpness. Different volumes of a solution $0.1 \mathrm{M}$ of $\mathrm{Na}_{2} \mathrm{EDTA}$ were added to real matrix samples to achieve final concentrations of $1 \%, 3 \%$ and $5 \%$. As observed in Figure S3 in SI, peak intensities increased for the majority of the compounds in the 
three water matrices along with the percentage of $\mathrm{Na}_{2} \mathrm{EDTA}$, indicating a better compound retention in the pre-concentration column. For those analytes that did not show any increase in the signal at any addition level of $\mathrm{Na}_{2}$ EDTA, especially in effluent samples, the decrease in the peak area was generally not higher than $5-10 \%$. Only 3-OH-ACM and FXT decreased their peak intensities markedly in influent wastewater samples. The signal improvement was more evident for river water samples, in which the increase of the peak area was observed for all the compounds (except for SPY and SMZ). The signal of the sulfonamide SMX was also remarkably improved in effluent and influent wastewaters. Figure S4 shows an example of signal improvement for SMX in influent and effluent wastewater. Finally, a volume corresponding to $5 \%$ of $\mathrm{Na}_{2}$ EDTA was selected.

\subsubsection{Sample volume (transfer time and elution time) and gradient} optimization

Sample load volume was optimized for the different water matrices. Real matrix volumes ranging from 1 to $5 \mathrm{~mL}$ were tested and different sample injection loops were used accordingly $(1,2$ and $5 \mathrm{~mL})$. In LC-LC methodologies, two different flow rates should be considered: the first from the loading pump which pushes the sample from the loop onto the pre-concentration column (Equan ${ }^{\mathrm{TM}}$ ), and the second from the elution pump, which goes through the analytical column and should be adjusted to obtain the best elution of the analytes from the column into the analyzer. Depending on the sample volume tested, the time required to evacuate the sample from the corresponding loops onto the Equan ${ }^{\mathrm{TM}}$ column (transfer time) was adjusted along with the load flow rate. The flow rate in this load step must be high enough not to let the matrix components to be retained in the Equan ${ }^{\mathrm{TM}}$ column, but not compromising the retention and concentration of the target analytes in it. After the sample loading, the 6-port valve switches and the analytes are transferred from the Equan ${ }^{\mathrm{TM}}$ column onto the analytical column at a lower flow rate. Then the valve switches again and the conventional elution step from the analytical column to the analyzer begins. The elution flow rate was set to $0.5 \mathrm{ml} \mathrm{min}^{-1}$ during the entire gradient; simultaneously during the elution step, the Equan ${ }^{\mathrm{TM}}$ column is cleaned and also preconditioned for the next sample (see Fig 1). The same mobile phases are used through both columns. Final gradients for the analysis of the three water matrices were configured by adjusting these parameters, and are given in Table S1 in SI. 
Recovery values for the different volumes tested for each water type are shown in Table S2 (SI), where a goodness range between $75 \%$ and $125 \%$ has been marked. Peak shape and matrix effects were also considered and eventually, a volume of $1 \mathrm{~mL}$ was chosen for influent wastewater, $2 \mathrm{~mL}$ for effluent wastewater and $5 \mathrm{~mL}$ for surface water.

\section{2. $\mathrm{MS}^{2}$ conditions}

MS conditions for a total of 12 PhACs, 20 metabolites and 11 deuterated internal standards were optimized. For 2 of them (DCF and glu-DCF), the best chromatographic responses were obtained working in $\mathrm{NI}$, whereas for the remaining compounds better responses where obtained in PI mode. In the case of 4-OH-DCF, the same good results were obtained in both $\mathrm{PI}$ and $\mathrm{NI}$ mode. In all cases, $[\mathrm{M}-\mathrm{H}]^{-}$for $\mathrm{NI}$ and $[\mathrm{M}+\mathrm{H}]^{+}$for $\mathrm{PI}$ mode were selected as precursor ions. Some additional pharmaceuticals were considered before the validation of the methodology. Due to its molecular similarity to the sulfonamides evaluated so far, SDZ and its acetylated metabolite acSDZ were included in the methodology scope after the optimization was finished. The same applied for acridine (ACRI), DZP and its metabolite desDZP, with a molecular structure similar to that of CBZ. Metoprolol (MTP) and its three major metabolites were also included at this stage as representative of the $\beta$-blockers, but were only considered in the analysis of wastewaters. As mentioned in section 2.3.2, two SRM transitions between the precursor ion and the two most abundant fragment ions were monitored for each compound, except for the isotopically labeled internal standards, for which only one transition was monitored as they are not found in the environment. Due to the poor fragmentation of the analgesic ACM, only one SRM transition could be registered for it. Following the Council Directive 96/23/EC implementation of 2002 [37] regarding the performance of analytical methods, other identification criteria considered were the chromatographic retention time (RT) of each of the analytes (differences between the RT in the sample and the RT in the standard curve should be within $\pm 2 \%$ ), and the ratio of both SRM transitions abundances, which should be in the range $\pm 20-30 \%$ of the same SRM ratio in the standard curve. Time-specific SRM windows were adjusted to the RTs of each target compound to improve the performance of the $Q q Q$, allowing both the cycle time and the dwell time to be automatically optimized and therefore gaining sensitivity and accuracy.

\subsection{Method performance}

\subsubsection{Matrix effects}


Different approaches are commonly used to decrease the amount of matrix components before LC-MS ${ }^{2}$ analyses, such as the improvement of the clean-up of the extracts or the optimization of the chromatographic gradient and flow [31]. The dilution of samples also decreases the amount of organic load entering the analyzer and can improve the signal, although it can reduce the sensitivity of the method considerably. Another parameter to be considered is the sweep gas of the interface, which helps to tackle with matrix compounds during the ionization, especially for dirty matrices such as influent or effluent wastewater samples. Undoubtedly the use of isotopically labeled internal standards is the most versatile procedure to compensate matrix effects (ME) during quantification, despite their usually high prices and the limited commercial availability for some of them.

Considering potential $\mathrm{ME}$, quantification was carried out following the internal standard calibration approach. Eight point calibration curves $\left(0.01-500 \mathrm{ng} \mathrm{L}^{-1}\right)$ were built for each of the analytes, following a least square linear regression analysis. Linearity was given as the regression coefficient $\left(r^{2}\right)$ and was always equal or above 0.999. The corresponding deuterated compounds used as internal standards were added to all the samples and standard solutions for the calibration curve at a concentration of $500 \mathrm{ng} \mathrm{L}^{-1}$ right before analysis. Matrix matched calibration curves were also built by means of standard addition for the three water matrices studied. The slopes of the resulting curves were compared to the slopes of the calibration curves built in HPLC water in order to evaluate signal suppression or enhancement during the analysis. ME\% values were calculated following equation [1]:

[1] $M E \%=100 \times\left(1-\frac{\left(\text { Slope }_{\text {std_addition }}\right)}{\text { Slope }_{\text {UHPLC_curve }}}\right)$

where ME\% is the matrix effect measured, slope std_addition $_{\text {is }}$ is the slope of the matrix matched calibration curve, and slope UHPL_curve is the slope of the calibration curve built in HPLC water.

ME\% values obtained are given in Table 2. As an example, Figure S5 in SI shows the standard calibration curves and the matrix matched calibration curves for effluent wastewater, influent wastewater and surface water for O-desVFX and 2-OH-CBZ. The notorious slope difference observed between the matrix-matched curves and the HPLC-water curves highlighted the signal suppression effect. 
Strong signal suppression ( $>50 \%$ ) was observed in the three types of water but

\subsubsection{Method validation}

After optimization, the analytical method developed was evaluated in terms of linearity, repeatability, accuracy, selectivity and sensitivity. As mentioned in the previous section, quantification was performed based on peak areas and by the internal standard calibration approach. Concentrations were estimated for the most abundant SRM transition selected. Eight point calibration curves were built at concentrations ranging from 0.1 to $500 \mathrm{ng}$ $\mathrm{L}^{-1}$; correlation coefficients were equal or higher than 0.999 for all the compounds. Accuracy was given as relative recovery values (R\%) of each compound in each water matrix at 3 different spike levels. Results are given in Table 3, and were higher than $75 \%$ with only a few exceptions with low recoveries (SDZ in influent R\% values, DZP in surface water R\% values). On the contrary, high R\% for some compounds such as ACM were also registered, which could be attributed to an operational mistake during the off-line standards analyses. Sensitivity is one of the method parameters enhanced when performing on-line SPE analysis. Despite the low sample volumes required, it has been proved that sensitivity is not affected but, on the contrary, improved considerably. Table 4 shows method limits of detection (MLOD) and quantification (MLOQ) for each of the three water matrices, calculated as the minimum detectable amount of analyte with a signal-to-noise ratio of 3 and 10, respectively. MLOD values were in the range of $0.1 \mathrm{ng} \mathrm{L}^{-1}$ (gluDCF-ACRI, norDZP) to $42.4 \mathrm{ng} \mathrm{L}^{-1}$ (des-SMX) for WWTP 
influent, 0.03-26.4 $\mathrm{ng} \mathrm{L}^{-1}$ (ACRI and ACM, respectively) for WWTP effluent and 0.01-73.2 $\mathrm{ng} \mathrm{L}^{-1}$ for surface water samples (VPM and 3-OH-ACM).

The precision of the method was evaluated by analyzing five consecutive times the corresponding water matrices spiked with a standard mixture of the analytes at concentrations ranging from 50 to $1000 \mathrm{ng} \mathrm{L}^{-1}$. The values of the estimated relative standard deviations (RSD\%) were below $5-10 \%$ for the majority of the analytes.

\subsection{Application to environmental samples}

The new methodology was applied to the determination of the target PhACs, metabolites and TPs in the three water matrices studied. As mentioned in section 2.2, 8 wastewater influent and effluent samples were taken in two different WWTPS. Results are shown in Table 5: samples 1-2 corresponded to a WWTP with CAS treatment and samples 3-6 corresponded to a WWTP with a MBR as secondary treatment. In both WWTPs, influent and effluents were taken as 24-hours integrated samples.

The highest concentrations in influent wastewater corresponded to $\mathrm{ACM}$, with concentrations up to $40.2 \mu \mathrm{g} \mathrm{L}^{-1}$. Similar results for this anti-inflammatory have been detected in previous studies [33]. Annual consumption of ACM is estimated in 700-1400 tons per year in Spain [38], and it is usually amongst the PhACs detected at highest levels [8, 39]. It should be highlighted that the metabolite 4-OH-DCF was present in all the influent samples at concentrations ranging between $53 \mu \mathrm{g} \mathrm{L}^{-1}$ and $366 \mu \mathrm{g} \mathrm{L}^{-1}$, with an average concentration ratio 4-OH-DCF/DCF of 0.6. These values are in accordance to the human metabolic excretion rate of DCF. A $60 \%$ of the oral dose of DCF is excreted in the urine as metabolites and conjugates, and $4-\mathrm{OH}-\mathrm{DCF}$ represents the $30 \%$ of the metabolic excretion rate of DCF [40]. In a previous study, a higher ratio (2.2) for this two compounds was found in influent wastewaters in Catalonia (Spain). The ratio O-desVFX/VFX (1.9-2.6) is in accordance with published data [41, 42] but was lower than those reported by other authors [43, 44]. Regarding the $\beta$-blocker MTP and its metabolites, MTPA/MTP ratios in the influent ranged between 60-80, and are in accordance with the metabolic excretion rates of these compounds $(60-65 \%$ of the MTP is excreted as MTPA and only a $3-10 \%$ is excreted in its original form) [45]. Concentrations of MTPA in the MBR effluents were higher than those detected in the influent in 3 of the 4 paired samples, with negative elimination rates ranging from $-48.8 \%$ (I6-E6) to $-171 \%$ (I3-E3). These results could indicate the formation of this compound as biodegradation product of the parent compound MTP; however, similarly to the metabolite, this $\beta$-blocker was unaltered during 
treatment, and similarly to MTPA, concentrations were higher in the effluent samples. Rubirola et al. also reported a similar behavior for MTPA and observed a concentration for this metabolite 10 times higher in effluent than in the influent wastewater of 2 urban WWTPs (CAS and MBR). In this study, these high concentrations were attributed to the generation of MTPA from atenolol, the major $\beta$-blocker present in influent wastewaters (up to 2 orders of magnitude higher than MTP) [46]. Radjenovic et al. [46] demonstrated that MTPA was also a primary degradation product for atenolol in MBR-sludge batch experiments, in which MTPA was detected simultaneously to the immediate degradation of atenolol and reached a $40 \%$ of the initial spiked concentration of atenolol after only 1 day. Despite atenolol is out of the scope of this work, atenolol has been frequently detected in MBR influent wastewaters $[8,47]$. Higher levels of the metabolites acSPY and norFXT compared to their corresponding parent compounds were also found in the influent samples.

Concentrations were significantly lower in the wastewater effluent samples; ACM was efficiently removed after MBR treatment, whereas it was still present in E1 and E2 after CAS treatment, at levels ranging from 0.47 to $0.53 \mu \mathrm{g} \mathrm{L}^{-1}$. Concentrations for $4-\mathrm{OH}-\mathrm{DCF}$ in the effluent were lower than in the influent, whereas those for DCF did not seem to vary significantly. This was reflected in the concentration ratio for both, which decreased to 0.4. Stülten et al. estimated a ratio of 0.7 in effluent wastewaters in Germany [48] , whereas Osorio et al. estimated even higher ratios (2.5-3) [49]. Furthermore, adDCF was detected in both CAS effluents, despite at low concentration (0.9-1.2 $\mathrm{ng} \mathrm{L}^{-1}$ ), whereas it was not present in the corresponding influent samples and so it can be considered as a likely degradation TP of either DCF or 4-OH-DCF. WWTPs designs and operational parameters may account for these differences. VFX and its two desmethylated metabolites were detected in all the effluent samples. CAS treatment seemed to be more efficient in the elimination of the metabolites than MBR, as the concentrations in the MBR effluents were in the same range that those detected in the influents. Regarding VFX, it is worth mentioning that its concentration in the effluent was higher or basically the same as in the influent samples taken from the WWTP with the CAS treatment, and in two of the four samples taken in the MBR. These results are in accordance with previous studies [41, 44]. This event has been discussed in different studies for other compounds (i.e. SMX) and it is usually attributed to the presence of conjugate compounds, that may not be included within the scope of the study, which revert back to their original compound during treatment $[50,51]$. This happened also for norFXT and for the TP adDCF, which was only detected in the effluent, fact that could be explained if adDCF was a 
potential intermediate product of DCF degradation (with elimination rates of $70-76 \%$ ). However, further studies should be carried out in order to confirm this possibility.

As expected, very few target compounds at low concentrations were detected in the water samples taken in a pristine river. CBZ was detected in the four samples, (2.4-4.1 $\mathrm{ng} \mathrm{L}^{-1}$ ). None of its corresponding metabolites or TPs was detected. VFX was not detected in any of these samples, but its main metabolite O-desVFX was detected in all of them, despite of low concentrations (1.57-2.35 $\left.\mathrm{ng} \mathrm{L}^{-1}\right)$. Non-point sources, such as residual water discharges from little villages upstream with no current wastewater treatment, high resilience to degradation of $\mathrm{CBZ}$ or the high consumption of the targeted drugs could explain the occurrence of these compounds in river waters with a low anthropogenic impact. In contrast, concentrations of target pollutants, both parent compounds and metabolites and TPs, in the second river studied, where samples were taken downstream of a WWTP were noticeably higher. For some of the compounds such as ACM, DCF, CBZ, VFX, their metabolites O-desVFX, N-desVFX and acSPY, concentration levels were comparable to those detected in some of the effluent samples studied. For instance, ACM was present at high concentrations, in the range of 287.3$577.9 \mathrm{ng} \mathrm{L}^{-1}$, and similar concentrations had already been detected in different samples taken in the Ebro River basin in a work by López-Serna et al. [10]. Altough river and effluent data are independent (river and effluent samples taken were not directly linked, as they were sampled in different year seasons and in different locations) the concentration ranges obtained help to fathom out the current status of receiving river waters, highlighting the ubiquity of the PhACs studied once discharged and increasing the concern regarding their potential ecotoxicity. DCF and CBZ and their hydroxylated metabolites were present in the four samples, with concentrations generally one order of magnitude higher for the parent compound. VFX and its two metabolites were also present in all the samples, but in this case, however, the concentration of O-desVFX was higher than that of VFX except for one sample.

In conclusion, metabolites and TPs are present at low concentrations in surface water, even in areas with low impact from WWTP discharges. These results highlight and reinforce the need of including metabolites and TPs in future screening and environmental studies. 


\section{Conclusions}

The analytical methodology presented in this work, based on LC-LC-ESI-MS ${ }^{2}$, has been proved to be a highly selective, sensitive and accurate for the detection of selected pharmaceutical and their corresponding metabolites and TPs in wastewaters and surface waters. It allows for a very efficient pre-concentration and clean-up of the samples, requiring a minimum manipulation and pretreatment (only the filtration step) and also a very low volume of the sample. The new methodology has allowed simultaneous analysis in both $\mathrm{NI}$ and $\mathrm{PI}$ mode without compromising the sensitivity of the analysis, obtaining LODs in the low $n \mathrm{~L} \mathrm{~L}^{-1}$ for most of the compounds. Matrix effects were also reduced by means of LC-LC clean up.

Results have demonstrated the widespread presence of the different metabolites and TPs in all the water matrices studied, at similar or even higher levels than the corresponding parent compounds. The presence of the TPs O-desVFX and N-desVFX in all the analyzed samples, in the case of O-desVFX generally at concentrations higher than those of VFX, should be emphasized. Similar results were obtained for acSPY and for desFXT in wastewaters. The TP adDCF was detected only in effluent wastewaters, suggesting the formation of this product during wastewater treatment. These results reinforce the need of including metabolites and TPs within the scope of future monitoring studies, as these data lead to a better understanding of biodegradation and attenuation processes of these PhaCs once discharged in the environment.

\section{Acknowledgments}

This study has been supported by the Generalitat de Catalunya (Consolidated Research Group: Catalan Institute for water Research 2014 SGR 291), by the Spanish Ministry of Economy and Competitiveness through the SCARCE project (Consolider-Ingenio 2010 CSD2009-00065) and by the European Union through the European Regional Development Fund (ERDF). MJ. García acknowledges the Beatriu de Pinos program (2014 BP-A 00245); Sara Rodriguez-Mozaz acknowledges the Ramon y Cajal program (RYC-2014-16707).

MJ. García would like to thank the support of C. Martins, S. Insa and M. Villagrasa during the development of the methodology, of $\mathrm{M}$. Llorca for her uninterested help with the set-up of the on-line configuration and L. Ferrando-Climent, M. Stefani and J. Mamo for her help during the sampling campaign. 


\section{References}

[1] K. Kümmerer, J. Environ. Manage. 90(8) (2009) 2354-2366.

[2] D. Fatta-Kassinos, S. Meric, A. Nikolaou, Anal. Bioanal. Chem. 399(1) (2010) 251-275.

[3] M. Gros, M. Petrovic, A. Ginebreda, D. Barceló, Environ. Int. 36(1) (2010) 15-26.

[4] P. Verlicchi, A. Galletti, M. Petrovic, D. Barceló, J. Hydrol. 389(3-4) (2010) 416-428.

[5] M. Clara, B. Strenn, M. Ausserleitner, N. Kreuzinger, Water Sci. Technol. 2004, pp. 29-36.

[6] S.C. Monteiro, A.B. Boxall, Rev. Environ. Contam. Toxicol. 202 (2010) 53-154.

[7] D. Fatta-Kassinos, S. Meric, A. Nikolaou, Anal. Bioanal. Chem. 399(1) (2011) 251-275.

[8] M. Gros, S. Rodríguez-Mozaz, D. Barceló, J. Chromatogr. A 1248 (2012) 104-121.

[9] R. López-Serna, S. Pérez, A. Ginebreda, M. Petrović, D. Barceló, Talanta 83(2) (2010) 410424.

[10] R. López-Serna, M. Petrovic, D. Barceló, Sci. Total Environ. 440 (2012) 280-289.

[11] M. Petrović, B. Škrbić, J. Živančev, L. Ferrando-Climent, D. Barcelo, Sci. Total Environ. 468469 (2013) 415-428.

[12] M. Cleuvers, Ecotox. Environ. Safe. 59(3) (2004) 309-315.

[13] T. Schulze, S. Weiss, E. Schymanski, P.C. von der Ohe, M. Schmitt-Jansen, R. Altenburger, G. Streck, W. Brack, Environ. Pollut.158(5) (2010) 1461-1466.

[14] M. Isidori, M. Lavorgna, A. Nardelli, L. Pascarella, A. Parrella, , Sci. Total Environ. 346(1-3) (2005) 87-98.

[15] D. Fatta-Kassinos, M.I. Vasquez, K. Kümmerer, Chemosphere 85(5) (2011) 693-709.

[16] E. Donner, T. Kosjek, S. Qualmann, K.O. Kusk, E. Heath, D.M. Revitt, A. Ledin, H.R. Andersen, Sci. Total Environ. 443 (2013) 870-876.

[17] Commission Directive 93/67/EEC

[18] M. García-Galán, S. González Blanco, R. López Roldán, S. Díaz-Cruz, D. Barceló, , Sci. Total Environ. 437 (2012) 403-412.,

[19] M.C. Dodd, H.P. Kohler, U. von Gunten, Environ. Sci. Technol. 43(7) (2009) 2498-504.

[20] M. Majewsky, D. Wagner, M. Delay, S. Bräse, V. Yargeau, H. Horn, Chemical Res. Toxicol.27(10) (2014) 1821-1828. 
[21] M.J. García-Galán, M.S. Díaz-Cruz, D. Barceló, Talanta 81(1-2) (2010) 355-366.

[22] T. Hata, S. Kawai, H. Okamura, T. Nishida, Biodegradation 21(5) (2010) 681-689.

[23] E. Marco-Urrea, M. Pérez-Trujillo, C. Cruz-Morato, G. Caminal, T. Vicent, J. Hazard. Mater.176(1-3) (2010) 836-842.

[24] L.A. Pérez-Estrada, S. Malato, W. Gernjak, A. Agüera, E.M. Thurman, I. Ferrer, A.R. Fernández-Alba, Environ. Sci. Technol.39(21) (2005) 8300-8306.

[25] A. Jelic, C. Cruz-Morató, E. Marco-Urrea, M. Sarrà, S. Perez, T. Vicent, M. Petrovic, D. Barceló, Water Res. 46(4) (2012) 955-964.

[26] F. Martínez, M.J. López-Muñoz, J. Aguado, J.A. Melero, J. Arsuaga, A. Sotto, R. Molina, Y. Segura, M.I. Pariente, A. Revilla, L. Cerro, G. Carenas, Water Res. 47(15) (2013) 5647-5658.

[27] M. Gros, M. Petrović, D. Barceló, Anal.Bioanal. Chem. 386(4) (2006) 941-952.

[28] A. Göbel, C.S. McArdell, M.J.F. Suter, W. Giger, Anal. Chem. 76(16) (2004) 4756-4764.

[29] S. Rodriguez-Mozaz, M.J. Lopez de Alda, D. Barceló, J. Chromatogr. A 1152(1-2) (2007) 97115.

[30] M. Gorga, M. Petrovic, D. Barcelo, J. Chromatogr. A 1295(21) (2013) 57-66.

[31] J.-P. Antignac, K. de Wasch, F. Monteau, H. De Brabander, F.o. Andre, B. Le Bizec, Anal. Chim. Acta 529 (2005) 129-136.

[32] M.J. García-Galán, S. Díaz-Cruz, D. Barceló, J. Chromatogr. A 1275(0) (2013) 32-40.

[33] M. Gros, S. Rodriguez-Mozaz, D. Barcelo, J. Chromatogr. A J. Chromatogr. A 1292(31) (2013) 173-88.

[34] J. Wang, P.R. Gardinali, Chemosphere 107 (2014) 65-73.

[35] E. Gracia-Lor, M. Ibáñez, T. Zamora, J. Sancho, F. Hernández, Environ. Sci. Pollut. Res. 21(8) (2014) 5496-5510.

[36] N.V. Heuett, S.R. Batchu, P.R. Gardinali, J. Hazard. Mater. 282 (2015) 41-50.

[37] COMMISSION DECISION of 12 August 2002. Official Journal of the European Communities (2002).

[38] S. Ortiz de García, G. Pinto Pinto, P. García Encina, R. Irusta Mata, Sci. Total Environ. 444 (2013) 451-465.

[39] M. Pedrouzo, F. Borrull, E. Pocurull, R.M. Marcé, Water Air Soil Poll. 217(1) (2010) 267281. 
[40] H. Stierlin, J.W. Faigle, A. Sallmann, W. Kung, W.J. Richter, H.P. Kriemler, K.O. Alt, T. Winkler, Xenobiotica 9(10) (1979) 601-610.

[41] M.P. Schlüsener, P. Hardenbicker, E. Nilson, M. Schulz, C. Viergutz, T.A. Ternes, Environ. Pollut.196 (2015) 247-256.

[42] A. Lajeunesse, C. Gagnon, S. SauvÃ@, Anal. Chem. 80(14) (2008) 5325-5333.

[43] P. Rúa-Gómez, W. Püttmann, Environ. Sci. Pollut. Res. 19(3) (2012) 689-699.

[44] G. Gasser, I. Pankratov, S. Elhanany, P. Werner, J. Gun, F. Gelman, O. Lev, Chemosphere 88(1) (2012) 98-105.

[45] S. Kern, R. Baumgartner, D.E. Helbling, J. Hollender, H. Singer, M.J. Loos, R.P. Schwarzenbach, K. Fenner, J. Environ. Monitor.12(11) (2010) 2100-2111.

[46] J. Radjenović, S. Pérez, M. Petrović, D. Barceló, J. Chromatogr. A 1210(2) (2008) 142-153.

[47] M.S. Kostich, A.L. Batt, J.M. Lazorchak, Environ. Pollut. 184 (2014) 354-359.

[48] D. Stülten, S. Zühlke, M. Lamshöft, M. Spiteller, Occurrence of diclofenac and selected metabolites in sewage effluents, Sci. Total Environ. 405(1-3) (2008) 310-316.

[49] V. Osorio, M. Imbert-Bouchard, B. Zonja, J.-L. Abad, S. Pérez, D. Barceló, J. Chromatogr. A 1347 (2014) 63-71.

[50] M.J. García-Galán, T. Frömel, J. Müller, M. Peschka, T. Knepper, S. Dïaz-Cruz, D. Barceló, Anal. Bioanal. Chem. 402(9) (2012) 2885-2896.

[51] A. Göbel, C.S. McArdell, A. Joss, H. Siegrist, W. Giger, Sci. Total Environ. 372(2-3) (2007) 361-371. 
Table 1. Chromatographic retention time and optimized $\mathrm{MS}^{2}$ transitions for the pharmaceuticals, human metabolites and TPs studied (in italics)

PhAC: pharmaceutical-parent drug; H-mtb: human metabolite; TP: transformation product; RT: chromatographic retention time (river samples). SRM: selected reaction monitoring. CE: collision energy. *: it is also commercialized as PhAC.

\begin{tabular}{|c|c|c|c|c|c|c|c|c|c|}
\hline $\begin{array}{c}\text { Therapeutic } \\
\text { Family }\end{array}$ & \multicolumn{2}{|l|}{ PPCP } & Abbreviation & Internal Standard & POLARITY & $\begin{array}{c}\text { RT } \\
(\min )\end{array}$ & $\begin{array}{l}\text { Precursor ion } \\
(\mathrm{m} / \mathrm{z})\end{array}$ & SRM1/SRM2 & CE1/CE2 \\
\hline \multirow{6}{*}{$\begin{array}{c}\text { Analgesics/ } \\
\text { anti- } \\
\text { inflammatories }\end{array}$} & Acetaminophen & PhAC & ACM & \multirow{3}{*}{ Acetaminophen- $d_{4}$} & + & 2,9 & 152,08 & 110,06 & 17 \\
\hline & OH-acetaminophen & $H-m t b$ & 3-OH-ACM & & + & 3 & 168,084 & $80.1 / 108.1$ & $28 / 16$ \\
\hline & Diclofenac & PhAC & DCF & & - & 8,8 & 293,941 & $250 / 214$ & $14 / 21$ \\
\hline & Diclofenac glucuronide & $H-m t b$ & gluDCF & \multirow[t]{2}{*}{ Diclofenac- $d_{4}$} & - & 7,6 & 470,023 & $192.9 / 249.8$ & $13 / 26$ \\
\hline & Diclofenac amide & $T P$ & $\operatorname{adDCF}$ & & + & 8,6 & 277,995 & $214 / 208$ & $28 / 25$ \\
\hline & 4-OH-diclofenac & $H-m t b$ & 4-OH-DCF & 4-OH-diclofenac- $d_{4}$ & + & 7,8 & 312,003 & $230 / 231$ & $32 / 18$ \\
\hline \multirow{11}{*}{$\begin{array}{l}\text { Psychiatric } \\
\text { drugs }\end{array}$} & Carbamazepine & PhAC & CBZ & \multirow{4}{*}{ Carbamazepine- $d_{10}$} & + & 6,9 & 237,149 & $193.2 / 194.2$ & $32 / 18$ \\
\hline & 10,11-ероху-carbamazepine & $H-m t b / T P$ & epo-CBZ & & + & 6,3 & 253,125 & $180.1 / 210.1$ & $29 / 13$ \\
\hline & 2-OH-carbamazepine & $H-m t b / T P$ & 2-OH-CBZ & & + & 6,3 & 253,138 & 210.2/167.1 & $19 / 35$ \\
\hline & Acridone & $H-m t b / T P$ & ACRO & & + & 6,4 & 196,056 & 167.02/139.01 & $31 / 48$ \\
\hline & Diazepam & PhAC & DZP & \multirow{2}{*}{ Diazepam- $d_{5}$} & + & 9,1 & 285,097 & $193.1 / 154$ & $29 / 25$ \\
\hline & Desmethyldiazepam & $H-m t b$ & norDZP & & + & 7,6 & 271,045 & $140 / 208.1$ & $29 / 28$ \\
\hline & Venlafaxine & PhAC & VFX & \multirow{3}{*}{ Venlafaxine- $\mathrm{d}_{6}$} & + & 6,2 & 278,24 & $58.1 / 260.3$ & $18 / 5$ \\
\hline & O-desmethylvenlafaxine & $H-m t b^{*}$ & O-desVFX & & + & 5,5 & 264,163 & $58.1 / 107$ & $18 / 31$ \\
\hline & N-desmethylvenlafaxine & $H-m t b$ & N-desVFX & & + & 6,1 & 264,155 & $44.1 / 121$ & $15 / 28$ \\
\hline & Fluoxetine & $P h A C$ & FXT & \multirow{2}{*}{ Fluoxetine- $d_{5}$} & + & 7,7 & 310,139 & $44.1 / 148$ & $17 / 10$ \\
\hline & Norfluoxetine & $H-m t b$ & & & + & 7,6 & 296,119 & $214 / 134$ & $24 / 4$ \\
\hline \multirow{4}{*}{ Antibiotics } & Sulfamethoxazole & PhAC & SMX & \multirow{4}{*}{ Sulfamethoxazole- $d_{4}$} & + & 6 & 254,096 & $92.1 / 156$ & $25 / 14$ \\
\hline & $N^{4}$-acetylsulfamethoxazole & $H-m t b$ & $\operatorname{acSMX}$ & & + & 6,1 & 296,043 & $134 / 65$ & $23 / 37$ \\
\hline & 4-nitro-sulfamethoxazole & $T P$ & n-SMX & & + & 7,9 & 284,075 & $75.1 / 189.1$ & $39 / 26$ \\
\hline & Desaminosulfamethoxazole & $T P$ & des-SMX & & + & 6,7 & 239,08 & 77.09/131.1 & $32 / 15$ \\
\hline
\end{tabular}




\begin{tabular}{|c|c|c|c|c|c|c|c|c|c|}
\hline & Sulfapyridine & PhAC & SPY & \multirow{6}{*}{$\begin{array}{l}\mathrm{N}^{4} \text {-acetylsulfapyridine- } \\
\mathrm{d}_{4}\end{array}$} & + & 5,2 & 250,101 & $156 / 92$ & $15 / 26$ \\
\hline & $N^{4}$-acetylsulfapyridine & $H-m t b$ & acSPY & & + & 5,4 & 292,092 & $134 / 198$ & $22 / 14$ \\
\hline & Sulfamethazine & $P h A C$ & SMZ & & + & 5,5 & 279,117 & $186 / 124$ & $16 / 22$ \\
\hline & $N^{4}$-acetylsulfamethazine & $H-m t b$ & $\operatorname{acSMZ}$ & & + & 5,4 & 321,114 & $134.1 / 186$ & $23 / 19$ \\
\hline & Sulfadiazine & $P h A C$ & SDZ & & + & 5,3 & 251,044 & $156 / 92$ & $14 / 26$ \\
\hline & $N^{4}$-acetylsulfadiazine & $H-m t b$ & $\operatorname{acSDZ}$ & & + & 5,2 & 293,052 & $134 / 65$ & $23 / 37$ \\
\hline \multirow{2}{*}{$\begin{array}{l}\text { Calcium } \\
\text { channel } \\
\text { blocker }\end{array}$} & Verapamil & $P h A C$ & VPM & \multirow{2}{*}{ Verapamil-d $\mathrm{d}_{6}$} & + & 7,4 & 455,195 & $165 / 150$ & $24 / 35$ \\
\hline & Norverapamil & $H-m t b$ & norVPM & & + & 7,3 & 441,195 & $165 / 150$ & $24 / 35$ \\
\hline \multirow{4}{*}{$\begin{array}{l}\text { B-blocking } \\
\text { agents }\end{array}$} & Metoprolol & $P h A C$ & MTP & \multirow{4}{*}{ Atenolol- $d_{7}$} & + & 4,7 & 268,14 & $116 / 77$ & $17 / 51$ \\
\hline & O-desmethylmetoprolol & $H-m t b$ & des-MTP & & + & 3,63 & 254,133 & $133 / 177.1$ & $48 / 24$ \\
\hline & Metoprolol acid & $H-m t b$ & MTPA & & + & 3,73 & 268,124 & $145 / 191$ & $24 / 17$ \\
\hline & $\alpha$-OH-metoprolol & $H-m t b$ & $\alpha-\mathrm{OH}-\mathrm{MTP}$ & & + & 3,51 & 284,138 & $74 / 116$ & $22 / 17$ \\
\hline
\end{tabular}


Table 2. Estimated matrix effects (ME\%) for the target analytes studied.

\begin{tabular}{|c|c|c|c|c|c|c|c|c|}
\hline & \multirow[b]{2}{*}{$\begin{array}{l}\text { Internal } \\
\text { standard }\end{array}$} & \multicolumn{2}{|c|}{$\begin{array}{c}\text { INFLUENT } \\
\text { WASTEWATER } \\
\end{array}$} & \multicolumn{2}{|c|}{$\begin{array}{c}\text { EFFLUENT } \\
\text { WASTEWATER } \\
\end{array}$} & \multicolumn{2}{|c|}{ SURFACE WATER } \\
\hline & & & ME\% & $\mathrm{ME}_{\text {std }} \%$ & ME\% & $\mathrm{ME}_{\text {Istd }} \%$ & ME\% & $\mathrm{ME}_{\text {Istd }} \%$ \\
\hline \multirow{6}{*}{$\begin{array}{c}\text { Analgesics/ } \\
\text { anti- } \\
\text { inflammatories }\end{array}$} & ACM & $A C A d$ & - & - & 39.9 & -10 & - & - \\
\hline & 3-OH-ACM & ACIVT-U 4 & - & - & 65.5 & 38.4 & - & - \\
\hline & DCF & & 61.3 & 0 & 84.1 & 0 & 24.1 & 11.1 \\
\hline & gluDCF & $D C F-d_{4}$ & 95.4 & 90 & - & - & 4.8 & 0 \\
\hline & adDCF & & 44.9 & 43.5 & 30.6 & 6.9 & 19.6 & 16.7 \\
\hline & 4-OH-DCF & 4-OH-DCF-d ${ }_{4}$ & 21.6 & -19.9 & 35.6 & 4.3 & 45.4 & 32.8 \\
\hline \multirow{12}{*}{$\begin{array}{l}\text { Psychiatric } \\
\text { drugs }\end{array}$} & CBZ & \multirow{5}{*}{$C B Z-d_{10}$} & 41.2 & -22.2 & 50.9 & 6.7 & 33.7 & 15.4 \\
\hline & epo-CBZ & & 24.7 & -50 & 50.2 & 0 & 25 & 20 \\
\hline & 2-OH-CBZ & & 59.8 & 10.5 & 95.8 & -11.1 & 38.2 & 0 \\
\hline & ACRO & & 46.3 & -9.1 & 95.2 & 23.5 & 21.6 & 0 \\
\hline & ACRI & & 48.42 & -10 & 72.04 & 52.6 & - & - \\
\hline & DZP & \multirow{2}{*}{$D Z P-d_{5}$} & 16.34 & 17.07 & 19.74 & 3.45 & 19.73 & 0 \\
\hline & norDZP & & -23.1 & 13.64 & 20.95 & 0 & 85.5 & 33.3 \\
\hline & VFX & $V F X-d_{6}$ & 49.1 & -27.6 & 98.2 & 4.3 & 34.2 & 0 \\
\hline & O-desVFX & \multirow{2}{*}{$O$-desVFX-d ${ }_{6}$} & 49 & -23.1 & 60.4 & 33.2 & 72.4 & 18.8 \\
\hline & N-desVFX & & 57.5 & -16.7 & 97.6 & 1.9 & 43.3 & 0 \\
\hline & FXT & \multirow{2}{*}{$F X T-d_{5}$} & 24.7 & 13.3 & 37.34 & -26.67 & 19.51 & 0 \\
\hline & norFXT & & 38.06 & 6.9 & -40 & 27.86 & 15.24 & 0 \\
\hline \multirow{10}{*}{ Antibiotics } & SMX & \multirow{4}{*}{$S M X-d_{4}$} & 38.7 & -18.4 & 97.1 & 3 & 73.6 & 31.6 \\
\hline & $\operatorname{acSMX}$ & & 70.1 & 29.2 & 74.4 & 31.8 & 63.9 & 12.5 \\
\hline & n-SMX & & 38.5 & 0 & 76.9 & 50 & 63.8 & 12.5 \\
\hline & des-SMX & & 49.7 & -17.7 & 60.14 & 4.8 & 40.7 & 69 \\
\hline & SPY & \multirow{6}{*}{$a c S P Y-d_{4}$} & 40.4 & -33.3 & 39.1 & 24.4 & 46.5 & 0 \\
\hline & acSPY & & 44.8 & -24 & 99.5 & 28.3 & 51.1 & 21.4 \\
\hline & SMZ & & 33.4 & 64.7 & 13.5 & -19.3 & 46 & 16.3 \\
\hline & acSMZ & & 42.2 & -30.2 & 98.9 & 7.6 & 56.9 & 37 \\
\hline & SDZ & & 68.7 & 22.2 & 95.8 & -8 & 55.7 & 25 \\
\hline & acSDZ & & 62.5 & 5.9 & 72.9 & 47.6 & 38.7 & 0 \\
\hline \multirow{2}{*}{$\begin{array}{l}\text { Calcium channel } \\
\text { blockers }\end{array}$} & VPM & \multirow{2}{*}{$V P M-d_{6}$} & -8.3 & 7.7 & 36.7 & 0 & 23.32 & 8.33 \\
\hline & norVPM & & 7.7 & -6.88 & 43.64 & 21.4 & 24.04 & 12.5 \\
\hline \multirow{4}{*}{$\begin{array}{l}\beta \text {-Blocking } \\
\text { agents }\end{array}$} & MTP & \multirow{4}{*}{$A T N-d_{7}$} & 46.71 & -4.1 & 39.38 & -16 & - & - \\
\hline & O-des-MTP & & 41.33 & -24 & 35.4 & 8 & - & - \\
\hline & MTPA & & 36.84 & -21.43 & 62.69 & 20 & - & - \\
\hline & $\alpha$-ОН-МTP & & 39.39 & -17.14 & 29.79 & 18.42 & - & - \\
\hline
\end{tabular}

$\mathrm{ME} \%$ : matrix effects estimated; $\mathrm{ME}_{\mathrm{Istd}}$ : matrix effects corrected with internal standard 
Table 3. Relative recovery values ( $R \%, n=3$ ) obtained for each of the water matrices investigated, at spike levels ranging from 50 to $1000 \mathrm{ng} \mathrm{L}^{-1}$.

\begin{tabular}{|c|c|c|c|c|c|c|c|c|c|c|c|c|c|c|c|c|c|c|c|}
\hline \multirow{3}{*}{$\begin{array}{c}\text { Therapeutic } \\
\text { Family } \\
\end{array}$} & \multirow{3}{*}{ COMPOUND } & \multicolumn{6}{|c|}{ INFLUENT } & \multicolumn{6}{|c|}{ EFFLUENT } & \multicolumn{6}{|c|}{ SURFACE WATER } \\
\hline & & \multicolumn{2}{|c|}{$100 \mathrm{ng} \mathrm{L}^{-1}$} & \multicolumn{2}{|c|}{$500 \mathrm{ng} \mathrm{L}^{-1}$} & \multicolumn{2}{|c|}{$1000 \mathrm{ng} \mathrm{L}^{-1}$} & \multicolumn{2}{|c|}{$50 \mathrm{ng} \mathrm{L}^{-1}$} & \multicolumn{2}{|c|}{$100 \mathrm{ng} \mathrm{L}^{-1}$} & \multicolumn{2}{|c|}{$500 \mathrm{ng} \mathrm{L}^{-1}$} & \multicolumn{2}{|c|}{$50 \mathrm{ng} \mathrm{L}^{-1}$} & \multicolumn{2}{|c|}{$100 \mathrm{ng} \mathrm{L}^{-1}$} & \multicolumn{2}{|c|}{$1000 \mathrm{ng} \mathrm{L}^{-1}$} \\
\hline & & $\mathrm{R}(\%)$ & RSD(\%) & $R(\%)$ & $\mathrm{RSD}(\%)$ & $\mathrm{R}(\%)$ & RSD(\%) & $R(\%)$ & RSD(\%) & $R(\%)$ & RSD(\%) & $R(\%)$ & $\mathrm{RSD}(\%)$ & $R(\%)$ & RSD(\%) & $R(\%)$ & RSD(\%) & $\mathrm{R}(\%)$ & RSD(\%) \\
\hline \multirow{6}{*}{$\begin{array}{c}\text { Analgesics/ } \\
\text { anti- } \\
\text { inflammatories }\end{array}$} & ACM & 112 & 13 & $>200$ & 12 & 111 & 9 & 94 & 7 & 86 & 8 & 53 & 7 & $>200$ & 3 & $>200$ & 8 & $>200$ & 2 \\
\hline & 3-OH-ACM & - & - & - & - & - & - & 76 & 7 & 120 & 8 & 56 & 4 & 85 & 6 & 28 & 10 & 3 & 5 \\
\hline & DCF & 89 & 2 & 60 & 4 & 47 & 4 & 85 & 8 & 89 & 3 & 100 & 5 & 197 & 2 & 89 & 3 & 104 & 3 \\
\hline & gluDCF & - & - & 147 & 11 & 87 & 14 & 48 & - & 113 & 6 & 169 & 3 & 47 & 16 & 72 & 3 & 83 & 2 \\
\hline & adDCF & 75 & 9 & 61 & 12 & 78 & 3 & 163 & 5 & 105 & 10 & 99 & - & 35 & 15 & 71 & 1 & 68 & 4 \\
\hline & 4-OH-DCF & 111 & 8 & 102 & 7 & 123 & 6 & 121 & 14 & 92 & 3 & 109 & 4 & 133 & 18 & 65 & 3 & 70 & 0 \\
\hline \multirow{12}{*}{$\begin{array}{l}\text { Psychiatric } \\
\text { drugs }\end{array}$} & CBZ & 95 & 2 & 113 & 1 & 133 & 2 & 96 & 1 & 113 & 3 & 79 & 5 & 113 & 8 & 85 & 1 & 94 & 1 \\
\hline & epo-CBZ & 73 & 4 & 78 & 5 & 78 & 3 & 154 & 4 & 99 & 2 & 101 & 5 & 58 & 15 & 54 & 6 & 75 & 0 \\
\hline & 2-OH-CBZ & 43 & 11 & 51 & 4 & 55 & 7 & 59 & 2 & 63 & 5 & 97 & 2 & 56 & 6 & 58 & 6 & 68 & 3 \\
\hline & ACRO & 62 & 1 & 66 & 4 & 78 & 1 & 91 & 2 & 111 & 4 & 112 & 2 & 114 & 12 & 98 & 4 & 138 & 2 \\
\hline & ACRI & 57 & 4 & 73 & 1 & 81 & 3 & 97 & 5 & 118 & 3 & 113 & 9 & - & - & - & - & - & - \\
\hline & DZP & 78 & 2 & 63 & 4 & 79 & 2 & 102 & 3 & 109 & 1 & 114 & 4 & 46 & 3 & 41 & 4 & 47 & 5 \\
\hline & norDZP & 92 & 1 & 122 & 1 & 96 & 2 & 65 & 7 & 73 & 2 & 67 & 2 & - & - & - & - & - & - \\
\hline & VFX & 138 & 2 & 124 & 5 & 153 & 1 & 62 & 4 & 93 & 0 & 104 & 1 & 126 & 4 & 92 & 4 & 96 & 4 \\
\hline & O-desVFX & 148 & 2 & 131 & 1 & 165 & 2 & 153 & 3 & 97 & 3 & 46 & 1 & 235 & 5 & 97 & 2 & 96 & 3 \\
\hline & N-desVFX & 53 & 8 & 62 & 2 & 80 & 13 & 81 & 2 & 169 & 6 & 101 & 4 & 125 & 15 & 179 & 2 & 155 & 4 \\
\hline & FXT & 103 & 5 & 91 & 2 & 89 & 4 & 121 & 10 & 138 & 12 & 113 & 1 & 80 & 8 & 85 & 4 & 91 & 6 \\
\hline & norFXT & 164 & 15 & 141 & 7 & $>200$ & 3 & 83 & 15 & 84 & 38 & 118 & 8 & 165 & 23 & 179 & 6 & 141 & 4 \\
\hline \multirow{5}{*}{ Antibiotics } & SMX & 88 & 4 & 114 & 2 & 147 & 3 & 53 & 5 & 100 & 1 & 81 & 3 & 62 & 16 & 97 & 2 & 87 & 6 \\
\hline & $\operatorname{acSMX}$ & 60 & 10 & 70 & 3 & 92 & 2 & 75 & 11 & 119 & 15 & 105 & 8 & 92 & 13 & 162 & 5 & 156 & 3 \\
\hline & n-SMX & $>200$ & 8 & $>200$ & 3 & $>200$ & 3 & 109 & 21 & 133 & 2 & 64 & 3 & 97 & 15 & 135 & 9 & 118 & 8 \\
\hline & des-SMX & 77 & 6 & 114 & 1 & 152 & 2 & 42 & 4 & 57 & 3 & 52 & 3 & 100 & 0 & 124 & 4 & 144 & 9 \\
\hline & SPY & 120 & 7 & 121 & 5 & 141 & 5 & 54 & 7 & 95 & 7 & 105 & 7 & 83 & 4 & 67 & 8 & 70 & 4 \\
\hline
\end{tabular}




\begin{tabular}{|c|c|c|c|c|c|c|c|c|c|c|c|c|c|c|c|c|c|c|c|}
\hline & acSPY & 109 & 3 & 107 & 5 & 129 & 6 & 87 & 3 & 85 & 4 & 88 & 3 & 85 & 3 & 77 & 3 & 98 & 5 \\
\hline & SMZ & 60 & 3 & 64 & 5 & 71 & 4 & 73 & 15 & 46 & 2 & 82 & 1 & 60 & 12 & 69 & 3 & 84 & 10 \\
\hline & $\operatorname{acSMZ}$ & 115 & 3 & 122 & 2 & 157 & 8 & 85 & 7 & 67 & 3 & 69 & 3 & 62 & 2 & 75 & 5 & 77 & 3 \\
\hline & SDZ & 20 & 13 & 18 & 4 & 19 & 2 & 33 & 10 & 56 & 4 & 37 & 5 & - & - & - & - & - & - \\
\hline & $\operatorname{acSDZ}$ & 81 & 3 & 85 & 6 & 96 & 6 & 79 & 5 & 85 & 4 & 81 & 3 & - & - & - & - & - & - \\
\hline \multirow{2}{*}{$\begin{array}{l}\text { Calcium } \\
\text { channel } \\
\text { blocker }\end{array}$} & VPM & & 1 & 56 & 5 & 56 & 1 & 84 & 6 & 93 & 8 & 91 & 2 & 94 & 9 & 87 & 1 & 105 & 4 \\
\hline & norVPM & 105 & 2 & 80 & 5 & 91 & 2 & 82 & 2 & 91 & 8 & 93 & 6 & 90 & 13 & 78 & 3 & 101 & 5 \\
\hline \multirow{4}{*}{$\begin{array}{l}\text { B-blocking } \\
\text { agents }\end{array}$} & MTP & 93 & 4 & 90 & 2 & 104 & 3 & 61 & 2 & 108 & 2 & 115 & 3 & - & - & - & - & - & - \\
\hline & O-desMTP & 95 & 4 & 91 & 4 & 119 & 1 & 68 & 7 & 100 & 7 & 90 & 3 & - & - & - & - & - & - \\
\hline & MTPA & 82 & 9 & 93 & 5 & 130 & 2 & 104 & 4 & 108 & 2 & 81 & 8 & - & - & - & - & - & - \\
\hline & $\alpha$-ОН-МТР & 95 & 1 & 95 & 1 & 120 & 2 & 93 & 6 & 84 & 2 & 90 & 3 & - & - & - & - & - & - \\
\hline
\end{tabular}


Table 4. Method limits of detection (LOD) and limits of quantification (LOQ), given in $\mathrm{ng} \mathrm{L}^{-1}$, and precision of the method expressed as relative standard deviation $(n=5, \%)$.

\begin{tabular}{|c|c|c|c|c|c|c|c|c|c|c|c|c|c|c|c|c|}
\hline \multirow[b]{3}{*}{$\begin{array}{l}\text { Therapeutic } \\
\text { Family }\end{array}$} & \multirow[b]{3}{*}{ COMPOUND } & \multicolumn{5}{|c|}{ INFLUENT } & \multicolumn{5}{|c|}{ EFFLUENT } & \multicolumn{5}{|c|}{ SURFACE WATER } \\
\hline & & \multirow{2}{*}{ LOD } & \multirow{2}{*}{ LOQ } & \multicolumn{3}{|c|}{$\begin{array}{c}\text { Repeatability (RSD } \\
\% \text { ) }\end{array}$} & \multirow{2}{*}{ LOD } & \multirow{2}{*}{ LOQ } & \multicolumn{3}{|c|}{$\begin{array}{c}\text { Repeatability (RSD } \\
\% \text { ) }\end{array}$} & \multirow{2}{*}{ LOD } & \multirow{2}{*}{ LOQ } & \multicolumn{3}{|c|}{$\begin{array}{c}\text { Repeatability (RSD } \\
\% \text { ) } \\
\end{array}$} \\
\hline & & & & 100 & 500 & 1000 & & & 50 & 100 & 500 & & & 50 & 100 & 500 \\
\hline \multirow{6}{*}{$\begin{array}{c}\text { Analgesics/ } \\
\text { anti- } \\
\text { inflammatories }\end{array}$} & ACM & 32,2 & 107,2 & 12,8 & 11,5 & 8,6 & 26,4 & 88,1 & 14,9 & 2,2 & 17,9 & 51,0 & 169,9 & 4,4 & 8,4 & 2,2 \\
\hline & 3-OH-ACM & 35,5 & 118,5 & 14,9 & 7,6 & 45 & 6,9 & 22,9 & - & - & - & 73,2 & 244,0 & - & - & - \\
\hline & DCF & 4,4 & 14,6 & 1,9 & 3,7 & 4 & 7,7 & 25,7 & 7,7 & 1,8 & 0,4 & 0,3 & 0,9 & 1,1 & 2,4 & 2,4 \\
\hline & gluDCF & 0,1 & 0,2 & - & 16,9 & 26,8 & 0,9 & 3,0 & - & - & - & 4,2 & 14,0 & 17,1 & 13,4 & 14,2 \\
\hline & adDCF & 7,1 & 23,6 & 11,8 & 0,4 & 2 & 0,3 & 0,9 & 6,1 & 5,9 & 5,5 & 0,9 & 3,1 & 4 & 0,34 & 6,2 \\
\hline & 4-DCF-OH & 13,8 & 45,9 & 1,2 & 3,6 & 3,3 & 0,8 & 2,8 & 7,9 & 6,8 & 4,1 & 0,1 & 0,2 & 1,9 & 3,9 & 4,8 \\
\hline \multirow{12}{*}{$\begin{array}{l}\text { Psychiatric } \\
\text { drugs }\end{array}$} & CBZ & 0,2 & 0,5 & 0,12 & 0,54 & 1,3 & 0,1 & 0,3 & 6,1 & 2,2 & 2,3 & 0,3 & 1,1 & 5,4 & 1,9 & 3,2 \\
\hline & epo-CBZ & 2,1 & 6,9 & 2,1 & 2,3 & 3,8 & 3,2 & 10,8 & 7,6 & 2,9 & 2,9 & 46,1 & 153,6 & 9,2 & 1,9 & 8,1 \\
\hline & $\mathrm{CBZ}-\mathrm{OH}$ & 5,9 & 19,6 & 6,8 & 4,2 & 3,2 & 0,9 & 3,0 & 9,7 & 1,5 & 2,5 & 4,8 & 16,0 & 5 & 16,4 & 10,9 \\
\hline & ACRO & 0,5 & 1,5 & 0,6 & 0,4 & 1,15 & 0,2 & 0,7 & 8,6 & 2,8 & 3,2 & 1,1 & 3,7 & 2,5 & 16,1 & 8,4 \\
\hline & ACRI & 0,1 & 0,4 & 3,8 & 4,5 & 4,6 & 0,03 & 0,1 & 2 & 0,5 & 3,6 & - & - & - & - & - \\
\hline & DZP & 0,2 & 0,5 & 2,1 & 0,6 & 6,8 & 0,04 & 0,1 & 7,5 & 1,6 & 2 & 0,0 & 0,1 & 1,5 & 2,1 & 5,2 \\
\hline & norDZP & 0,1 & 0,3 & 1,8 & 3 & 7,1 & 0,1 & 0,3 & 10,6 & 2,4 & 1,8 & 0,0 & 0,1 & 32,6 & 12,7 & - \\
\hline & VFX & 1,4 & 4,6 & 4 & 0,9 & 5,2 & 0,3 & 0,9 & 3,9 & 9,6 & 1,7 & 0,1 & 0,2 & 5,8 & 3,7 & 7,8 \\
\hline & O-desVFX & 0,8 & 2,7 & 2,6 & 0,9 & 5 & 0,4 & 1,3 & 8,4 & 2,9 & 2,1 & 0,2 & 0,6 & 4,5 & 3,5 & 4 \\
\hline & N-desVFX & 0,8 & 2,7 & 8,02 & 1,7 & 12,9 & 1,9 & 6,3 & 5,5 & 3,7 & 3,6 & 0,1 & 0,2 & 8,6 & 1,3 & 3,5 \\
\hline & FXT & 3,5 & 11,6 & 1,9 & 1,2 & 4,6 & 0,4 & 1,5 & 9,9 & 1,4 & 0,3 & 0,0 & 0,1 & 3,6 & 11,1 & 1,8 \\
\hline & norFXT & 5,5 & 18,3 & 3,6 & 2,7 & 3,8 & 4,1 & 13,8 & 2,4 & 4 & 2,4 & 0,3 & 0,9 & 11,3 & 10,8 & 3,8 \\
\hline \multirow{2}{*}{ Antibiotics } & SMX & 4,6 & 15,3 & 2,1 & 1,2 & 3,9 & 3,8 & 12,6 & 10,9 & 3,4 & 1,1 & 2,9 & 9,6 & 13,9 & 0,2 & 3,8 \\
\hline & $\operatorname{acSMX}$ & 4,2 & 13,9 & 7,4 & 3,5 & 1,6 & 2,4 & 8,1 & 7,2 & 5,7 & 3,1 & 3,9 & 12,9 & 10,3 & 14,1 & 7,4 \\
\hline
\end{tabular}




\begin{tabular}{|c|c|c|c|c|c|c|c|c|c|c|c|c|c|c|c|c|}
\hline & n-SMX & 42,4 & 141,3 & 11,7 & 4,5 & 6,1 & 0,5 & 1,7 & 11,3 & 16,9 & 12,4 & 0,2 & 0,8 & 5,1 & 16,7 & 4,9 \\
\hline & des-SMX & 30,5 & 101,8 & 0,12 & 0,64 & 1,9 & 1,8 & 5,9 & 13,9 & 5,4 & 2,6 & 8,2 & 27,3 & 3,7 & 2,3 & 0,9 \\
\hline & SPY & 1,3 & 4,2 & 5,2 & 1,2 & 9,4 & 1,1 & 3,8 & 6,7 & 1,3 & 4 & 1,3 & 4,2 & 14 & 5,8 & 7,2 \\
\hline & acSPY & 2,1 & 7,1 & 0,5 & 3,5 & 9,6 & 1,2 & 3,9 & 5,6 & 2,7 & 5,2 & 0,7 & 2,4 & 3,6 & 1,4 & 5,7 \\
\hline & SMZ & 4,0 & 13,4 & 1,3 & 2,2 & 4 & 0,5 & 1,6 & 4,6 & 4,1 & 2,1 & 0,1 & 0,2 & 7,3 & 3 & 2,3 \\
\hline & acSMZ & 0,2 & 0,6 & 0,1 & 5,7 & 6,2 & 1,0 & 3,4 & 12,6 & 1,2 & 3 & 0,8 & 2,7 & 5 & 0,7 & 7,7 \\
\hline & SDZ & 15,2 & 50,6 & 16,9 & 7,5 & 8,8 & 6,0 & 19,9 & 8,1 & 0,7 & 6,8 & 9,9 & 32,9 & 13,5 & 5,2 & 3,1 \\
\hline & acSDZ & 10,9 & 36,5 & 1,6 & 1,3 & 2,8 & 4,1 & 13,7 & 11,9 & 6,4 & 1,5 & 2,6 & 8,5 & 2,3 & 1,7 & 5,1 \\
\hline \multirow{2}{*}{$\begin{array}{c}\text { Calcium channel } \\
\text { blockers }\end{array}$} & VPM & 0,4 & 1,4 & 1,3 & 1,4 & 2,2 & 0,1 & 0,2 & 4,2 & 5,9 & 8,4 & 0,0 & 0,0 & 10,2 & 13,7 & 2,8 \\
\hline & norVPM & 0,5 & 1,7 & 1,4 & 1 & 4,2 & 0,1 & 0,4 & 9,9 & 2,8 & 5,9 & 0,1 & 0,3 & 10,1 & 8,4 & 8,1 \\
\hline \multirow{4}{*}{$\begin{array}{l}\beta \text {-Blocking } \\
\text { agents }\end{array}$} & MTP & 0,4 & 1,4 & 4,0 & 3,2 & 1,9 & 0,3 & 0,9 & 2,7 & 1,2 & 3,9 & - & - & - & - & - \\
\hline & O-DMTP & 8,5 & 28,3 & 0,3 & 2,3 & 0,4 & 9,2 & 30,6 & 1,2 & 0,2 & 0,8 & - & - & - & - & - \\
\hline & MTPA & 5,2 & 17,2 & 2,9 & 2,3 & 1,3 & 4,2 & 13,9 & 1,6 & 2,0 & 3,0 & - & - & - & - & - \\
\hline & $\alpha$-HMTP & 1,1 & 3,5 & 4,1 & 4,2 & 2,9 & 0,8 & 2,7 & 3,1 & 0,7 & 2,6 & - & - & - & - & - \\
\hline
\end{tabular}


Table 5. Concentration values ( $\mathrm{ng} \mathrm{L}^{-1}$ ) obtained for the target pharmaceuticals, metabolites and transformation products investigated in influent and effluent wastewater and in surface water (pristine river and river downstream of WWTPs discharge points) 


\begin{tabular}{|c|c|c|c|c|c|c|c|c|c|c|c|c|c|c|c|c|c|c|c|c|c|c|c|c|c|}
\hline & & \multicolumn{12}{|c|}{ INFFLUENT } & \multicolumn{12}{|c|}{ EFFLUENT } \\
\hline & & I1 & $\begin{array}{l}\text { RSD } \\
(\%)\end{array}$ & 12 & $\begin{array}{l}\text { RSD } \\
\text { (\%) }\end{array}$ & 13 & $\begin{array}{l}\text { RSD } \\
\text { (\%) }\end{array}$ & 14 & $\begin{array}{l}\text { RSD } \\
\text { (\%) }\end{array}$ & 15 & $\begin{array}{l}\text { RSD } \\
\text { (\%) }\end{array}$ & 16 & $\begin{array}{l}\text { RSD } \\
\text { (\%) }\end{array}$ & E1 & $\begin{array}{l}\text { RSD } \\
(\%)\end{array}$ & E2 & $\begin{array}{l}\text { RSD } \\
\text { (\%) }\end{array}$ & E3 & $\begin{array}{l}\text { RSD } \\
\text { (\%) }\end{array}$ & E4 & $\begin{array}{l}\text { RSD } \\
\text { (\%) }\end{array}$ & E5 & $\begin{array}{l}\text { RSD } \\
\text { (\%) }\end{array}$ & E6 & $\begin{array}{l}\text { RSD } \\
\text { (\%) }\end{array}$ \\
\hline \multirow{6}{*}{$\begin{array}{l}\text { Analgesics/ } \\
\text { anti- } \\
\text { inflammatories }\end{array}$} & ACM & 9374,9 & 9,9 & 2926,2 & 12,1 & 24980,0 & 2,5 & 39577,8 & 14,1 & 40180,4 & 6,3 & 25144,1 & 0,5 & 476,5 & 5,7 & 532,2 & 12,4 & $<\angle O Q$ & - & n.d. & - & $<\angle O Q$ & - & n.d. & - \\
\hline & 3-OH-ACM & n.d. & - & n.d. & - & n.d. & - & n.d. & - & n.d. & - & n.d. & - & n.d. & & n.d. & - & n.d. & - & n.d. & - & n.d. & - & n.d. & - \\
\hline & DCF & 560,5 & 6,2 & 454,6 & 4,9 & 710,6 & 1,4 & 1090,0 & 3,3 & 842,5 & 4,2 & 441,1 & 4,1 & 175,5 & 3,4 & 116,0 & 1,5 & 215,0 & 1,9 & 256,8 & 2,9 & 227,0 & 1,4 & 477,1 & 8,6 \\
\hline & 4-OH-DCF & 583,4 & 4,8 & 566,4 & 6,5 & 6818,8 & 5,4 & 12397,6 & 2,3 & 11545,9 & 7,9 & 396,4 & 4,5 & 3,9 & 6,4 & 74,9 & 3,5 & 5291,5 & 0,9 & 7015,8 & 0,6 & 5959,7 & 2,3 & 730,8 & 10,3 \\
\hline & gluDCF & n.d. & - & n.d. & - & n.d. & - & n.d. & - & n.d. & - & n.d. & - & n.d. & & n.d. & - & n.d. & - & n.d. & - & n.d. & - & n.d. & - \\
\hline & adDCF & n.d. & - & n.d. & - & n.d. & - & n.d. & - & n.d. & - & n.d. & - & 0,9 & 4,9 & 1,2 & 23,0 & $<\angle O Q$ & - & n.d. & - & n.d. & - & n.d. & - \\
\hline \multirow{12}{*}{$\begin{array}{l}\text { Psychiatric } \\
\text { drugs }\end{array}$} & CBZ & 275,1 & 6,8 & 67,1 & 1,8 & 74,4 & 3,1 & 97,7 & 1,6 & 101,3 & 1,6 & 83,7 & 1,8 & 30,6 & 4,5 & 18,1 & 1,4 & 91,9 & 0,2 & 107,8 & 14,9 & 76,6 & 1,5 & 144,6 & 8,1 \\
\hline & epo-CBZ & 93,2 & 2,6 & 30,4 & 12,8 & n.d. & - & n.d. & - & n.d. & - & $32,4^{*}$ & - & 32,7 & 3,7 & 0,0 & - & n.d. & - & n.d. & - & n.d. & - & 87,4 & 10,6 \\
\hline & 2-OH-CBZ & 2261,0 & 9,3 & 76,8 & 7,8 & 23,7 & 4,0 & $28.8^{*}$ & - & 35,8 & 0,6 & 35,0 & 3,5 & 22,5 & 5,6 & 13,3 & 0,6 & $<\angle O Q$ & - & n.d. & - & 0,0 & - & 64,2 & 11,6 \\
\hline & ACRO & 6,1 & 1,0 & 2,3 & 1,0 & n.d. & - & n.d. & - & 1,5 & 18,4 & n.d. & - & 1,2 & 2,6 & 1,5 & 1,8 & 0,7 & 1,5 & n.d. & - & $<\angle O Q$ & - & n.d. & - \\
\hline & ACRI & n.a. & - & n.a. & - & n.d. & - & n.d. & - & n.d. & - & n.d. & - & n.a. & & n.a. & & n.d. & - & n.d. & - & n.d. & - & n.d. & - \\
\hline & DZP & 9,4 & 18,7 & 4,1 & 2,3 & 1,7 & 17,6 & 2,7 & 8,7 & n.d. & - & 4,4 & 10,4 & $<L O Q$ & & $<\angle O Q$ & - & 1,4 & 3,1 & 2,2 & 7,2 & 0,7 & 7,6 & 4,0 & 16,8 \\
\hline & norDZP & 40,1 & 9,5 & 20,7 & 6,6 & 12,5 & 6,1 & 22,4 & 0,9 & 20,6 & 3,0 & 7,3 & 1,2 & 6,3 & 4,0 & 4,1 & 2,0 & 14,9 & 0,9 & 18,7 & 5,4 & 14,0 & 4,5 & 15,1 & 16,4 \\
\hline & VFX & 792,9 & 5,2 & 277,5 & 3,7 & 228,9 & 2,7 & 348,2 & 4,2 & 304,8 & 1,4 & 181,3 & 1,3 & 872,3 & 1,0 & 268,9 & 2,1 & 191,3 & 3,1 & 244,3 & 6,9 & 175,7 & 0,5 & 209,8 & 12,9 \\
\hline & O-desVFX & 1714,2 & 7,2 & 519,4 & 5,3 & 447,0 & 3,5 & 861,4 & 5,8 & 700,6 & 5,4 & 465,9 & 1,1 & 180,9 & 1,3 & 128,4 & 10,3 & 506,4 & 1,4 & 613,0 & 2,7 & 467,8 & 2,7 & 684,3 & 11,4 \\
\hline & N-desVFX & 763,1 & 14,6 & 87,5 & 5,3 & 28,3 & 7,3 & 47,0 & 12,3 & 41,5 & 7,2 & 27,2 & 5,8 & 39,5 & 15,0 & 17,2 & 9,5 & 25,0 & 0,1 & 33,0 & 2,3 & 27,2 & 5,3 & 35,1 & 30,8 \\
\hline & FXT & $19,8^{*}$ & - & 19,1 & 1,8 & $25,3^{*}$ & - & n.d. & - & n.d. & - & 73,5 & 1,3 & 9,3 & 10,9 & 16,1 & 12,7 & 10,8 & 8,8 & 21,0 & 1,1 & 14,8 & 21,2 & 10,7 & 5,7 \\
\hline & norfXT & 3314,7 & 9,0 & 44,2 & 7,8 & 373,2 & 8,6 & 584,8 & 10,7 & 486,0 & 3,6 & 391,6 & 2,1 & 291,7 & 7,2 & 187,4 & 10,3 & 552,5 & 0,8 & 894,6 & 5,9 & 720,4 & 7,3 & 0,0 & - \\
\hline \multirow{10}{*}{ Antibiotics } & SMX & 976,8 & 7,2 & 308,8 & 2,9 & 119,4 & 4,1 & 207,9 & 6,2 & 243,7 & 5,7 & 237,1 & 3,4 & 98,2 & 7,0 & 19,6 & 7,6 & 47,0 & 0,5 & $63,6^{*}$ & - & 40,1 & 3,2 & 71,5 & 1,4 \\
\hline & acSMX & 1557,5 & 10,9 & 106,9 & 1,8 & 95,3 & 3,7 & 144,0 & 3,1 & 148,8 & 3,8 & 231,2 & - & n.d. & & n.d. & - & n.d. & - & n.d. & - & n.d. & - & n.d. & - \\
\hline & n-SMX & n.d. & - & n.d. & - & n.d. & - & n.d. & - & n.d. & - & n.d. & - & n.d. & & n.d. & - & n.d. & - & n.d. & - & n.d. & - & n.d. & - \\
\hline & des-SMX & n.d. & - & n.d. & - & n.d. & - & n.d. & - & n.d. & - & n.d. & - & n.d. & & n.d. & - & n.d. & - & n.d. & - & n.d. & - & n.d. & - \\
\hline & SPY & 97,5 & 11,5 & 186,5 & 17,2 & 85,0 & 3,6 & 179,9 & 5,0 & 153,1 & 2,2 & 105,8 & 6,3 & $<$ LOQ & & $<\angle O Q$ & - & 15,9 & 7,0 & 14,7 & 4,5 & 14,1 & 1,4 & n.d. & - \\
\hline & acSPY & 285,4 & 2,5 & $147,1^{*}$ & - & 145,6 & 3,7 & 291,6 & 6,8 & 227,7 & 4,2 & 83,5 & 4,0 & n.d. & & n.d. & - & n.d. & - & n.d. & - & n.d. & - & n.d. & - \\
\hline & SMZ & n.d. & - & n.d. & - & n.d. & - & n.d. & - & n.d. & - & n.d. & - & $<$ LOQ & & $<\angle O Q$ & - & 0,0 & - & 0,0 & - & 0,0 & - & 0,0 & - \\
\hline & acSMz & n.d. & - & n.d. & - & n.d. & - & n.d. & - & n.d. & - & n.d. & - & n.d. & & n.d. & - & n.d. & - & n.d. & - & n.d. & - & n.d. & - \\
\hline & SDZ & n.d. & - & n.d. & - & 679,3 & 5,8 & 1228,2 & 6,7 & 1106,4 & 3,4 & n.d. & - & n.d. & & n.d. & - & n.d. & - & n.d. & - & n.d. & - & n.d. & - \\
\hline & acSDZ & n.d. & - & n.d. & - & n.d. & - & $<\angle O Q$ & - & n.d. & - & n.d. & - & n.d. & & n.d. & - & n.d. & - & n.d. & - & n.d. & - & n.d. & - \\
\hline \multirow{2}{*}{$\begin{array}{l}\text { Calcium channel } \\
\text { blockers }\end{array}$} & VPM & 23,8 & 6,1 & 5,2 & 10,1 & 4,6 & 4,2 & $<L O Q$ & - & 5,9 & 10,2 & n.d. & - & 0,4 & 27,6 & $<L O Q$ & - & 2,0 & 8,6 & 3,0 & 8,3 & 2,2 & 7,9 & 7,7 & 8,1 \\
\hline & norVPM & $29 *$ & - & 2,6 & 6,7 & $<\angle O Q$ & - & n.d. & - & $<\angle O Q$ & - & 6,1 & 15,0 & 1,5 & 8,2 & 1,1 & 18,1 & 1,1 & 19,1 & 1,7 & 12,0 & 1,1 & 6,0 & 0,0 & - \\
\hline \multirow{4}{*}{$\begin{array}{c}\text { B-blocking } \\
\text { agents }\end{array}$} & MTP & n.a. & - & n.a. & - & 11,9 & 7,1 & 14,7 & 5,5 & 12,8 & 1,7 & 24,5 & 2,3 & 12,8 & 1,7 & & & 59,7 & 10,1 & 59,7 & 10,1 & 45,7 & 2,3 & 40,6 & 11,8 \\
\hline & O-desMTP & n.a. & - & n.a. & - & n.d. & - & n.d. & - & n.d. & - & - & - & n.d. & & & & $<\angle O Q$ & - & n.d. & - & $<\angle O Q$ & - & n.d. & - \\
\hline & MTPA & n.a. & - & n.a. & - & 740,7 & 4,5 & 1093,8 & 1,5 & 1088,6 & 2,0 & 724,5 & 2,3 & 1088,6 & 2,0 & & & 2007,5 & 8,7 & 1018,9 & 0,4 & 1896,3 & 1,1 & 1077,9 & 7,7 \\
\hline & $\alpha$-ОН-МTP & n.a. & - & n.a. & - & 20,5 & 9,8 & 27,1 & 5,0 & 25,1 & 5,0 & 22,9 & 7,6 & 25,1 & 5,0 & & & n.d. & - & $<L O Q$ & - & n.d. & - & 7,6 & 33,8 \\
\hline
\end{tabular}


Table 5. (cont).

\begin{tabular}{|c|c|c|c|c|c|c|c|c|c|c|c|c|c|c|c|c|c|}
\hline & & \multicolumn{8}{|c|}{ PRISTINE RIVER } & \multicolumn{8}{|c|}{ IMPACTED RIVER } \\
\hline & & U1 & $\begin{array}{l}\text { RSD } \\
(\%)\end{array}$ & U2 & $\begin{array}{l}\text { RSD } \\
(\%) \\
\end{array}$ & U3 & $\begin{array}{l}\text { RSD } \\
(\%) \\
\end{array}$ & U4 & $\begin{array}{l}\text { RSD } \\
(\%)\end{array}$ & D1 & $\begin{array}{l}\text { RSD } \\
(\%) \\
\end{array}$ & D2 & $\begin{array}{l}\text { RSD } \\
(\%) \\
\end{array}$ & D3 & $\begin{array}{l}\text { RSD } \\
(\%) \\
\end{array}$ & D4 & $\begin{array}{l}\text { RSD } \\
(\%) \\
\end{array}$ \\
\hline \multirow{6}{*}{$\begin{array}{c}\text { Analgesics/ } \\
\text { anti- } \\
\text { inflammatories }\end{array}$} & ACM & n.d. & - & n.d. & - & n.d. & - & n.d. & - & 287,3 & 19,9 & 355,77 & 13,8 & 577,9 & 4,9 & $302,26^{*}$ & - \\
\hline & 3-OH-ACM & n.d. & - & n.d. & - & n.d. & - & n.d. & & n.d. & - & n.d. & - & n.d. & - & n.d. & - \\
\hline & DCF & n.d. & - & n.d. & - & n.d. & - & n.d. & - & 165,6 & 4,8 & 157,1 & 11,1 & 212,9 & 10,6 & 358,5 & 1,2 \\
\hline & 4-OH-DCF & 1,1 & - & n.d. & - & n.d. & - & 0,4 & - & 50,9 & 21,0 & 65,8 & 17,7 & 7,6 & 21,6 & 460,9 & 12,2 \\
\hline & gluDCF & n.d. & - & n.d. & - & n.d. & - & n.d. & - & n.d. & - & n.d. & - & n.d. & - & n.d. & - \\
\hline & adDCF & n.d. & - & n.d. & - & n.d. & - & n.d. & - & n.d. & - & n.d. & - & n.d. & - & n.d. & - \\
\hline \multirow{12}{*}{$\begin{array}{l}\text { Psychiatric } \\
\text { drugs }\end{array}$} & CBZ & 2,8 & 5,2 & 2,2 & 2,8 & 1,7 & 4,1 & 3,3 & 2,4 & 160,9 & 6,6 & 162,1 & 16,0 & 180,9 & 18,9 & 998,9 & 10,9 \\
\hline & epo-CBZ & n.d. & - & n.d. & - & n.d. & - & n.d. & - & n.d. & - & 135,7 & 4,9 & n.d. & - & n.d. & - \\
\hline & 2-OH-CBZ & n.d. & - & n.d. & - & n.d. & - & n.d. & - & 56,8 & 7,5 & 64,5 & 4,2 & n.d. & - & 431,9 & 14,4 \\
\hline & ACRO & n.d. & - & n.d. & - & n.d. & - & n.d. & - & 8,6 & 47,2 & $8,4^{*}$ & - & $5,6^{*}$ & - & 35,5 & 38,9 \\
\hline & ACRI & n.a. & & n.a. & & n.a. & & n.a. & & n.a. & - & n.a. & - & n.a. & - & n.a. & - \\
\hline & DZP & n.d. & - & n.d. & - & n.d. & - & n.d. & - & $6,2^{*}$ & - & n.d. & - & 7,4 & 4,2 & 20,1 & 3,3 \\
\hline & norDZP & 0,2 & - & 0,2 & 4,6 & n.d. & - & n.d. & - & 24,8 & 3,9 & 52,3 & 58,8 & 18,1 & 45,9 & 230,6 & 15,1 \\
\hline & VFX & n.d. & - & n.d. & - & n.d. & - & n.d. & - & 258,8 & 8,5 & 309,5 & 0,2 & 340,7 & 1,7 & 1830,1 & 13,1 \\
\hline & O-desVFX & 2,1 & 7,9 & 1,6 & - & 1,0 & - & 2,4 & 7,8 & 354,2 & 2,1 & 754,7 & 18,6 & 504,6 & 10,7 & 86,1 & 4,9 \\
\hline & N-desVFX & n.d. & - & n.d. & - & n.d. & - & 1,4 & 18,7 & 0,5 & 30,4 & 0,5 & 13,3 & 0,3 & 58,1 & 2,6 & 42,2 \\
\hline & FXT & n.d. & - & n.d. & - & n.d. & - & n.d. & - & 36,1 & 13,1 & 13,5 & 9,0 & 18,9 & 26,8 & 85,1 & 4,1 \\
\hline & norFXT & n.d. & - & n.d. & - & n.d. & - & n.d. & - & n.d. & - & n.d. & - & n.d. & - & n.d. & - \\
\hline \multirow{10}{*}{ Antibiotics } & SMX & n.d. & - & n.d. & - & n.d. & - & n.d. & - & n.d. & - & n.d. & - & n.d. & - & $13,4^{*}$ & - \\
\hline & acSMX & n.d. & - & n.d. & - & n.d. & - & n.d. & - & n.d. & - & n.d. & - & n.d. & - & $<\angle O Q$ & - \\
\hline & $n-S M X$ & n.d. & - & n.d. & - & n.d. & - & n.d. & - & n.d. & - & n.d. & - & n.d. & - & n.d. & - \\
\hline & des-SMX & n.d. & - & n.d. & - & n.d. & - & n.d. & - & n.d. & - & n.d. & - & n.d. & - & n.d. & - \\
\hline & SPY & n.d. & - & n.d. & - & n.d. & - & n.d. & - & $11,7^{*}$ & - & 12,5 & 0,2 & n.d. & - & 15,6 & 9,1 \\
\hline & acSPY & n.d. & - & n.d. & - & n.d. & - & n.d. & - & 19,7 & 1,9 & 17,3 & 3,9 & 6,8 & 6,0 & $14.4^{*}$ & - \\
\hline & SMZ & n.d. & - & n.d. & - & n.d. & - & n.d. & - & n.d. & - & n.d. & - & n.d. & - & n.d. & - \\
\hline & acSMz & 0,5 & - & n.d. & - & n.d. & - & 0,9 & - & n.d. & - & n.d. & - & n.d. & - & n.d. & - \\
\hline & SDZ & n.d. & - & n.d. & - & n.d. & - & n.d. & - & n.d. & - & n.d. & - & n.d. & - & n.d. & - \\
\hline & acSDZ & n.d. & - & n.d. & - & n.d. & - & n.d. & - & n.d. & - & n.d. & - & n.d. & - & n.d. & - \\
\hline \multirow{2}{*}{\begin{tabular}{|c|}
$\begin{array}{c}\text { Calcium channel } \\
\text { blockers }\end{array}$ \\
\end{tabular}} & VPM & n.d. & - & n.d. & - & n.d. & - & n.d. & - & 5,6 & 2,9 & 6,1 & 16,8 & 12,3 & 13,8 & 96,3 & 7,2 \\
\hline & norVPM & n.d. & - & n.d. & - & n.d. & - & n.d. & - & n.d. & - & $2,9 *$ & - & 4,5 & 4,5 & 16,2 & 18,4 \\
\hline \multirow{4}{*}{$\begin{array}{c}\beta \text {-blocking } \\
\text { agents }\end{array}$} & MTP & n.a. & - & n.a. & - & n.a. & - & n.a. & - & n.a. & - & n.a. & - & n.a. & - & n.a. & - \\
\hline & O-desMTP & n.a. & - & n.a. & - & n.a. & - & n.a. & - & n.a. & - & n.a. & - & n.a. & - & n.a. & - \\
\hline & MTPA & n.a. & - & n.a. & - & n.a. & - & n.a. & - & n.a. & - & n.a. & - & n.a. & - & n.a. & - \\
\hline & $\alpha$-OH-MTP & n.a. & - & n.a. & - & n.a. & - & n.a. & - & n.a. & - & n.a. & - & n.a. & - & n.a. & - \\
\hline
\end{tabular}


n.d.: not detected (<LOD)

n.a.: not analized

$*$ : only one value out of the 3 triplicates 
Table 5. Concentration values $\left(\mathrm{ng} \mathrm{L}^{-1}\right)$ obtained for the target pharmaceuticals, metabolites and transformation products investigated in influent and effluent was

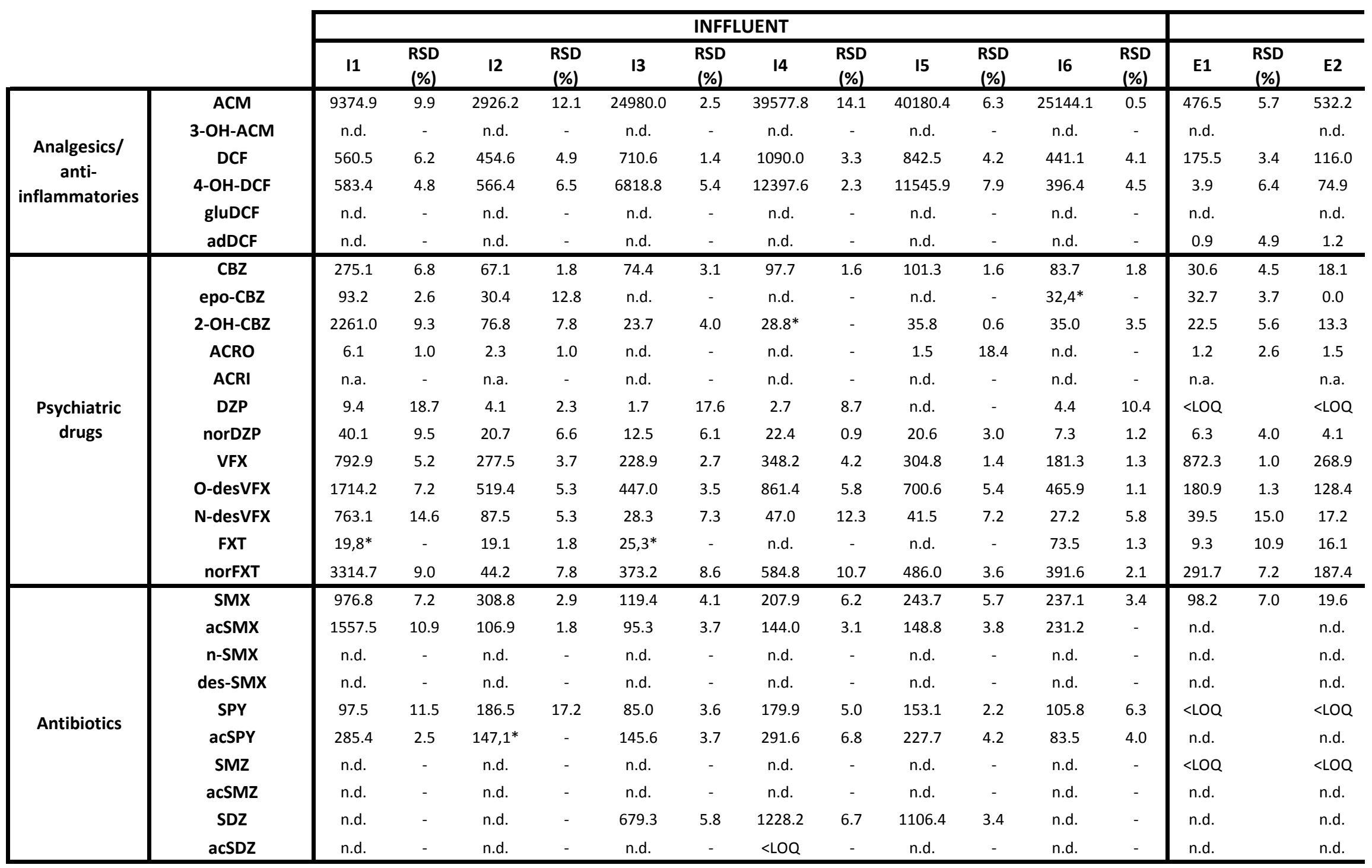




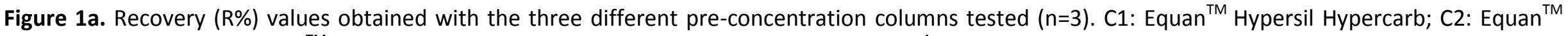
Hypersil Gold Aqua; C3: Equan ${ }^{\mathrm{TM}}$ Hypersil Gold PFP. Water solutions concentration: $100 \mathrm{ng} \mathrm{L}^{-1}$.

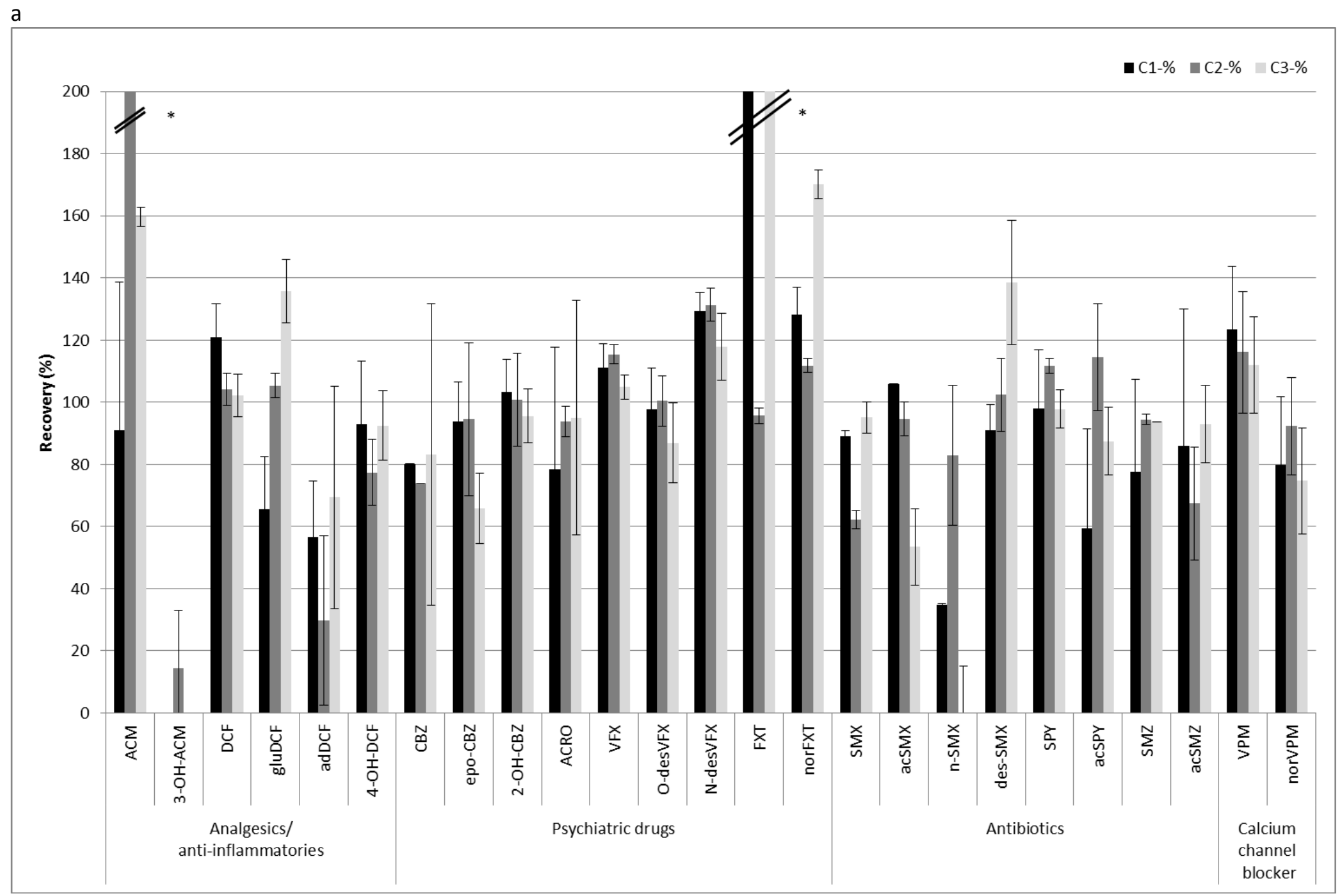


* : R\% > 200\% 

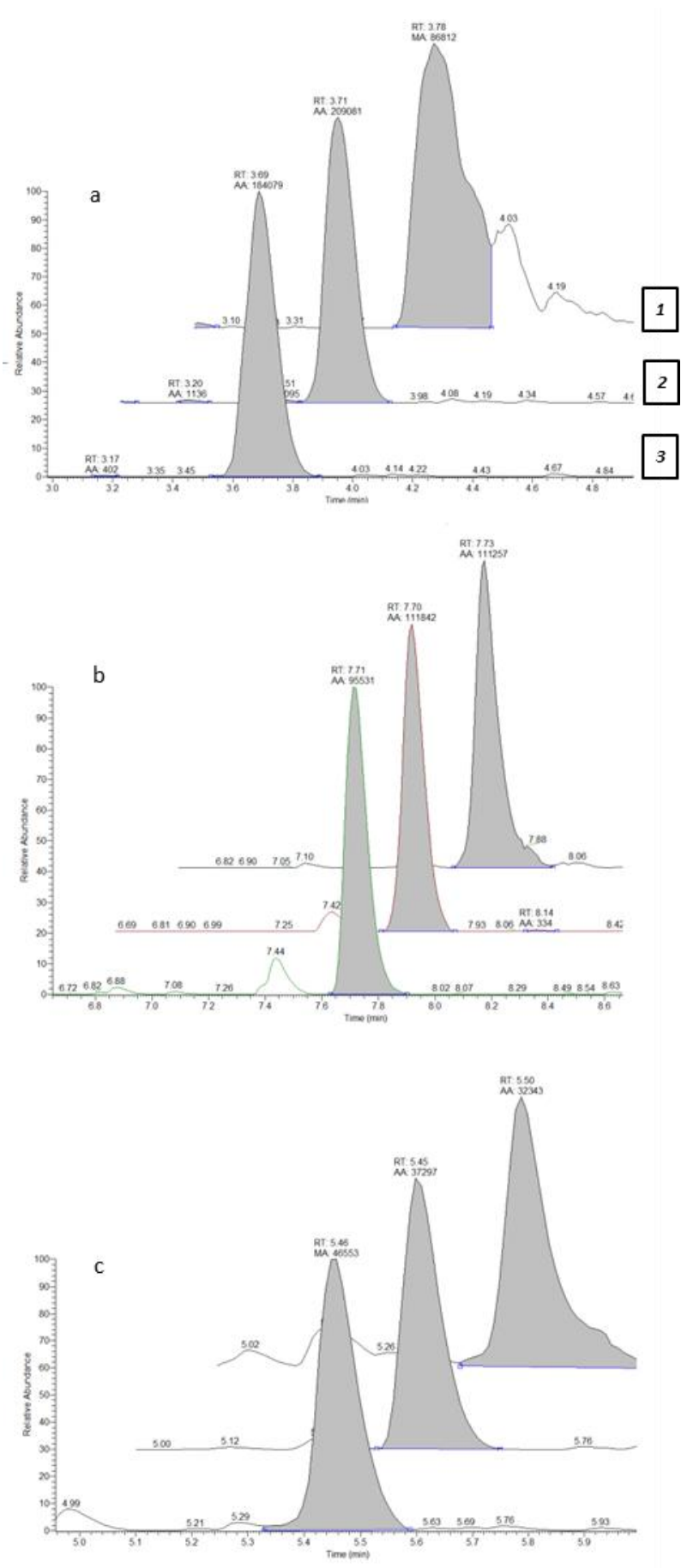

Figure 1b. Peak shapes obtained for SPY (a), 4-OH-DCF (b) and acSMX (c) using three different pre-concentration columns (1: Hypersil ${ }^{\mathrm{TM}}$ Hypercarb ; 2 : Hypersil $^{\mathrm{TM}}$ Gold Aqua; 3: Hypersil $^{\mathrm{TM}}$ Gold PFP; the same order applies for a), b) and c)). 
SUBMISSION CHECK LIST

- E-mail address and full postal address

All necessary files have been uploaded, and contain:

- Keywords

- All figure captions (included in the Figures individual files)

- All tables (including title, description, footnotes)

- Manuscript has been 'spell-checked' and 'grammar-checked'

- References are in the correct format for this journal

- All references mentioned in the Reference list are cited in the text, and vice versa

- Permission has been obtained for use of copyrighted material from other sources (including the Internet) Printed version of figures (if applicable) in color or black-and-white

- NO color prints are required for this manuscript 


\section{LIST OF THREE POTENTIAL REVIEWERS}

Dr. Ester Heath

Department of Environmental Sciences,

Jozef Stefan Institute, Jamova 39, 1000,

Ljubljana,

Slovenia.

ester.heath@ijs.si

Dr. Sandra Babic

Department of analytical chemistry

Faculty of Chemical Engineering and Technology

Zagreb (Croatia)

sandra.babic@fkit.hr

Dr. Maria Jose Gomez Ramos

National Research Centre for Environmental Toxicology

Faculty of Health and Behavioural Sciences, Queensland University

Australia

m.gomezramos@uq.edu.au

Dr. Maria Jesus Martinez Bueno

Department of chemistry and physics

University of Almeria (Spain)

mjbueno@ual.es 
Supplementary Material
Click here to download Supplementary Material: Supplementary info.docx

Supplementary Material
Click here to download Supplementary Material: Supplementary info.docx

X

